This is the final peer-reviewed accepted manuscript of:

Sorrentino, R., Carlson, K. J., Bortolini, ... \& Benazzi, S. (2020). Morphometric analysis of the hominin talus: Evolutionary and functional implications. Journal of Human Evolution, 142, 102747.

The final published version is available online at: https://doi.org/10.1016/i.jhevol.2020.102747

Rights / License:

The terms and conditions for the reuse of this version of the manuscript are specified in the publishing policy. For all terms of use and more information see the publisher's website.

This item was downloaded from IRIS Università di Bologna (https://cris.unibo.it/)

When citing, please refer to the published version. 


\section{Morphometric analysis of the hominin talus: Evolutionary and functional implications}

Rita Sorrentino $^{\mathrm{a}, \mathrm{b},{ }^{*},}$, Kristian J. Carlson ${ }^{\mathrm{c}, \mathrm{d}}$, Eugenio Bortolini ${ }^{\mathrm{b}}$, Caterina Minghetti ${ }^{\mathrm{b}}$, Francesco

Feletti $^{\mathrm{e}}$, Luca Fiorenza ${ }^{\mathrm{f}, \mathrm{g}}$, Stephen Frost ${ }^{\mathrm{h}}$, Tea Jashashvili ${ }^{\mathrm{i}, \mathrm{j}}$, William Parr ${ }^{\mathrm{k}}$, Colin Shaw ${ }^{1}$, Anne Su ${ }^{\mathrm{m}}$, Kevin Turley ${ }^{\mathrm{h}}$, Stephen Wroe ${ }^{\mathrm{n}}$, Timothy M. Ryan ${ }^{\mathrm{o}}$, M. Giovanna Belcastro ${ }^{\mathrm{a}, \mathrm{p}}$, Stefano Benazzi ${ }^{\mathrm{b}, \mathrm{q}}$

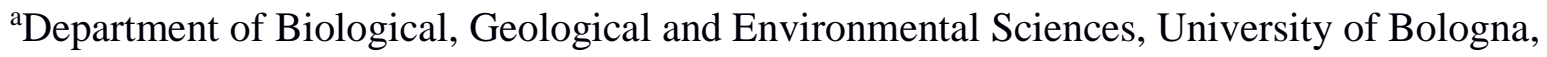
Bologna 40126, Italy.

${ }^{b}$ Department of Cultural Heritage, University of Bologna, Ravenna 48121, Italy.

${ }^{\mathrm{c}}$ Department of Integrative Anatomical Sciences, Keck School of Medicine, University of Southern California, Los Angeles 90089, USA.

${ }^{\mathrm{d}}$ Evolutionary Studies Institute, University of the Witwatersrand, Palaeosciences Centre, Private Bag 3, Wits 2050, South Africa.

${ }^{\text {e}}$ Department of Diagnostic Imaging, Ausl Romagna, S.Maria delle Croci Hospital, Ravenna 48121, Italy.

${ }^{\mathrm{f}}$ Department of Anatomy and Developmental Biology, Monash University, Clayton, VIC 3800, Australia.

gEarth Sciences, University of New England, Armidale NSW 2351, Australia.

hDepartment of Anthropology, University of Oregon, Eugene, OR, 97403-1218, USA.

${ }^{\mathrm{i}}$ Molecular Imaging Center, Department of Radiology, Keck School of Medicine, University of Southern California, Los Angeles 90089, USA.

jDepartment of Geology and Paleontology, Georgian National Museum, 0105 Tbilisi, Georgia.

${ }^{\mathrm{k} S u r g i c a l}$ and Orthopaedic Research Laboratory, Prince of Wales Hospital, University of New South Wales, Sydney 1466, Australia.

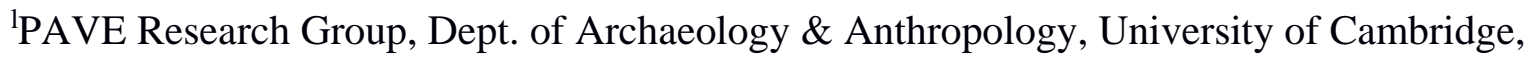
Cambridge CB2 3QG, United Kingdom.

${ }^{\mathrm{m}}$ School of Health Sciences, Cleveland State University, Cleveland, OH 44195, USA.

${ }^{\mathrm{n}}$ Function, Evolution and Anatomy Research Laboratory, Zoology Division, School of

Environmental and Rural Science, University of New England, New South Wales 2351, Australia.

${ }^{\circ}$ Department of Anthropology, Pennsylvania State University, University Park, PA 16802, USA.

${ }^{\mathrm{p}}$ ADES, UMR 7268 CNRS/Aix-Marseille Université/EFS, Aix-Marseille Université,

CS80011, Bd Pierre Dramard, Marseille Cedex 15, 13344, France.

${ }^{\mathrm{q}}$ Department of Human Evolution, Max Planck Institute for Evolutionary Anthropology, Leipzig 04103, Germany.

*Corresponding author: Rita Sorrentino, Department of Biological, Geological and Environmental Sciences, University of Bologna, Via Selmi 3, 40126 Bologna, Italy. Phone number: +39 0544936730. Email address: rita.sorrentino2@unibo.it 


\section{Abstract}

The adoption of bipedalism is a key benchmark in human evolution that has impacted talar morphology. Here, we investigate talar morphological variability in extinct and extant hominins using a 3D geometric morphometric approach. The evolutionary timing and appearance of modern human-like features and their contributions to bipedal locomotion were evaluated on the talus as a whole, each articular facet separately, and multiple combinations of facets. Distinctive suites of features are consistently present in all fossil hominins, despite the presence of substantial interspecific variation, suggesting a potential connection of these suites to bipedal gait. A modern human-like condition evolved in navicular and lateral malleolar facets early in the hominin lineage compared to other facets, which demonstrate more complex morphological variation within Homininae. Interestingly, navicular facet morphology of Australopithecus afarensis is derived in the direction of Homo, whereas more recent hominin species such as $A$. africanus and $A$. sediba retain more primitive states in this facet. Combining the navicular facet with the trochlea and the posterior calcaneal facet as a functional suite, however, distinguishes Australopithecus from Homo in that the medial longitudinal arch had not fully developed in the former. Our results suggest that a more everted foot and stiffer medial midtarsal region are adaptations that coincide with the emergence of bipedalism, while a high medial longitudinal arch emerges later in time, within Homo. This study provides novel insights into the emergence of talar morphological traits linked to bipedalism and its transition from a facultative to an obligate condition.

Keywords: bipedalism, hominin evolution, talar, functional morphology. 


\section{Introduction}

Modern humans and at least some extinct hominins are the only primates that have engaged in routine or obligate bipedal locomotion. This feature remains the primary evolutionary hallmark used to separate extinct and extant hominins from apes, although how and when terrestrial bipedalism emerged in the hominin lineage are some of the longest-standing questions in palaeoanthropology (Richmond et al., 2001; Kivell and Schmitt, 2009; Harcourt-Smith, 2010). While the capacity for upright walking in the earliest hominins between $7 \mathrm{Ma}$ and $4 \mathrm{Ma}$ (i.e., Sahelanthropus tchadensis, Orrorin tugenensis, Ardipithecus kadabba, Ardipithecus ramidus) is still debated (Haile-Selassie, 2001; Wolpoff et al., 2002; Zollikofer et al., 2005; Richmond and Jungers, 2008; Almécija et al., 2013; Lovejoy et al., 2009; White et al., 2009; Crompton, 2016), it is broadly accepted that terrestrial bipedalism was adaptive behavior in australopiths, as confirmed by the $3.6 \mathrm{Ma}$ footprints from Laetoli, generally attributed to $A$. afarensis (Ward, 2002; DeSilva, 2009; Raichlen et al., 2010; Drapeau and Harmon, 2013; Ryan et al., 2018). However, australopiths also retained adaptive skeletal characteristics that are linked to arboreality, suggesting that the overall locomotor repertoire of African hominins between 4 and 2 Ma consisted of a greater range of locomotor modes performed at different frequencies than later hominins (e.g., $H$. erectus) (Stern and Susman, 1983; Haile-Selassie et al., 2012; Prang, 2016a).

It is accepted that most species of Homo are obligate bipeds, but there are divergent opinions about the bipedal capability of the first members of the genus. Some have interpreted derived postcranial morphology in early Homo (e.g., increased relative hind limb length) as critical for long distance walking and running (Bramble and Lieberman, 2004; Haeusler and McHenry, 2004; Pontzer, 2012; Antón et al., 2014). Others have noted that pre-erectus Homo share morphological features and skeletal proportions with Australopithecus, suggesting that obligate, fully-committed terrestrial bipedalism only emerged with $H$. ergaster/erectus (Ruff, 2008; Pontzer et al., 2010; Antón et al., 2014; Hatala et al., 2016b). However, primitive retentions present in Late Pleistocene $H$. naledi (e.g., pedal phalanges more curved than in $H$. sapiens) and $H$. floresiensis (e.g., long foot relative to the leg and short hallux) suggest that skeletal features used to infer modern human gait 
and posture may even be unique to $H$. sapiens (Jungers et al., 2009; Harcourt-Smith et al., 2015; Harcourt-Smith, 2016).

Despite this uncertainty, it is clear that over approximately 7 million years hominins eventually evolved a suite of specialized anatomical features (e.g., anteriorly placed foramen magnum, Sshape vertebral column, broad and flattened ribcage, wide and short pelvis, long lower limb, stable knee, relatively long and robust ankle region, an arched foot), which together facilitated energetically efficient bipedal gait kinematics and torso orthograde posture (Aiello and Dean, 1990; Bramble and Lieberman, 2004; Harcourt-Smith, 2010).

Among all adaptations that have evolved in the hominin locomotor system, those of the foot are highly specialized and most directly reflective of an interaction with the substrate (ground or branch) (Aiello and Dean, 1990; Kidd, 1999; Harcourt-Smith and Aiello, 2004; McNutt et al., 2018). During a single step of the gait cycle, the human foot transitions from acting as a compliant shock absorber at heel strike to a rigid lever at toe-off (i.e., via the windlass mechanism) (Griffin et al., 2015). Structurally, the human foot is defined as a twisted plate forming transverse and longitudinal arches (Sarrafian, 1987). When standing, the modern human foot is an elastic, arched structure that actively works to maintain the body's stability, adjusting itself with small sideward displacements of the talus (Huson, 1991).

The human talus occupies a key position in the ankle, as: 1) it is the tenon of the ankle mortise, 2) it sustains the body's entire weight while transmitting load anteriorly to the navicular and inferiorly to the calcaneus, 3) it facilitates plantar- and dorsal flexion, and contributes to abduction-adduction and inversion-eversion of the foot, and 4) it is part of the bony infrastructure forming the medial longitudinal arch (Aiello and Dean, 1990; Huson, 1991; Griffin et al., 2015).

In the foot, the talus is isolated from the other bones by a fibrous capsule and it takes part in the ankle (talocrural) joint, the talocalcaneal joints and the talonavicular joint. The talus itself consists of three main parts (i.e., body, neck, and head) and seven articular facets. The superior surface of the body (trochlea facet) articulates with the inferior surface of the tibia, as the predominant weightbearing joint surface in the ankle. The medial malleolar facet articulates with the tibial malleolus, while the lateral malleolar facet accommodates the fibular malleolus, and both the tibia and fibula 
bind the talus in the ankle mortise. Posteriorly, the talar body has two processes (medial and lateral tubercles) separated by the flexor hallucis longus (FHL) groove. The talar head possesses a convex expanded surface for articulation with the navicular bone (i.e., the navicular facet). Inferiorly, three articular facets (posterior, medial and anterior) comprise the joint with the calcaneus. The large, concave posterior calcaneal facet facilitates complex motion and prevents excessive inversion and eversion. Anterior and medial calcaneal facets are often joined into a single articular surface (Steele and Bramblett, 1988).

The talus is also unique compared to other foot bones as no major foot or leg muscle is directly attached to it. From a functional point of view this means that all talar movements are passive, i.e. they result from forces acting on the talus after being transmitted from other bones. These forces can be transmitted in two ways: through direct contact and pressure at articular facets, and through tension of ligaments and capsular soft tissue. When viewed in this manner, relevance of articular facet morphology in determining potential functional contributions of the talus to foot and leg function during locomotion is apparent (Aiello and Dean, 1990; Huson, 1991; Parr et al., 2014). Because of this critical structural role of the talus, several studies have focused on comparative hominoid talar morphology in order to identify talar features linked to functional stability and bipedal locomotor behavior. The common consensus is that, when compared with great apes, humans exhibit a low horizontal angle of the talar head in a transverse plane, increased neck and head torsion in a coronal plane, and increased plantar head inclination in a sagittal plane that may be related to the adducted hallux and to the presence of a longitudinal arch. A flatter talar head exhibited by modern humans may indicate decreased midtarsal mobility, which together with torsion of the talar head may help the foot behave as a rigid lever during toe-off. Human calcaneal facets are relatively flat, which inhibits mobility at the subtalar joint presumably to guarantee stability at the ankle during bipedal gait. A flatter and more squared trochlea with equally high rims would account for a neutral foot position with the leg orthogonally oriented, as well as a reduced capacity for dorsiflexion. Ultimately, modern humans differ from non-human African apes (hereafter called African apes) in exhibiting less flared medial and lateral malleolar facets. Although the functional implications of malleolar flaring remains controversial, it is often associated with arboreal 
locomotor behavior, as opposed to terrestrial locomotor behavior (Elftman and Manter, 1935; Day and Wood, 1968; Latimer et al., 1987; Gebo, 1992; Gebo and Schwartz, 2006; DeSilva, 2009; Lovejoy et al., 2009; Turley and Frost, 2013; DeSilva et al., 2013, 2019; Prang, 2016a,b; McNutt et al., 2018).

Because the talus is a common element in the fossil record and its morphology is clearly linked to locomotor behavior, there is considerable literature evaluating the presence of derived features presumably related to greater stability and support of body weight during bipedal walking and standing (from here defined as "bipedal features") in extinct hominins (Day and Wood, 1968; Rhoads and Trinkaus, 1977; Latimer et al., 1987; Kidd et al., 1996; Harcourt-Smith, 2002; Harcourt-Smith and Aiello, 2004; Gebo and Schwartz, 2006; Jungers et al., 2009; White et al., 2009; DeSilva and Throckmorton, 2010; Pontzer et al., 2010; Parr et al., 2011a; Zipfel et al., 2011; Su et al., 2013; Turley and Frost, 2013, 2014; Harcourt-Smith et al., 2015; Prang, 2015; Prang, 2016a, Su and Carlson, 2017). However, the majority of these studies have tended to consider the whole talus rather than distinct articular facets or the timing of their evolution, i.e., their individual and combined importance during the acquisition of modern human-like terrestrial bipedalism. In the present study, we aim to: 1) quantify hominin talar variation using a (semi)landmark-based approach and compare the results with previous analyses of talar external form, 2) formally assess the contribution of individual and combined facets in identifying bipedal features (i.e., features linked to obligate bipedalism in a broad modern human sample), and 3) evaluate the appearance of human-like talar characteristics in taxa by sampling different periods of the human evolutionary lineage.

Furthermore, we test the suggestion that hominin tali from Sterkfontein Member 4 presently attributed to $A$. africanus may belong to different species by performing a phenetic distance analysis (Clarke, 2013; Su and Carlson, 2017).

Finally, we seek to demonstrate whether or not recognizing modern human-like traits in individual talar facets and/or suites of facets may enable the extraction of more information from fragmentary fossil tali that would help in their taxonomic assignment and functional interpretation. 


\section{Materials and Methods}

\subsection{Data collection}

The sample consists of 161 tali (Supplemental Online Materials (SOM) Tables S1 and S2) from $H$. sapiens (81), Gorilla gorilla (31), Pan troglodytes (29), and extinct hominins (20). The extinct hominin tali include fossils attributed to Australopithecus afarensis (A.L. 288-1), Australopithecus africanus (StW 88, StW 363, StW 486), Australopithecus sediba (U.W. 88-98), Paranthropus robustus (TM 1517), Homo habilis/ Paranthropus boisei (OH 8), Homo sp. / Paranthropus boisei (KNM-ER 1464, KNM-ER 1476), Homo sp. (KNM-ER 813), Homo erectus (KNM-ER 5428, D4110), Homo naledi (U.W. 101-1417, U.W. 101-1417), Homo neanderthalensis (EM 3519, Krapina 235, Krapina 237, SP4B, Ferrassie 1, Ferrasie 2), and Homo floresiensis (LB1-15).

In the present work we first included Pongo specimens in our sample. Results show that no fossil hominins plot close to the Pongo range, while they plot instead between African apes and $H$. sapiens (SOM Fig. S1). When Pongo is included, differences between Pan and Gorilla are considerably reduced in morphospace and the two groups overlap. At the same time, the distance between African apes and $H$. sapiens is short and differences among fossil hominins are difficult to appreciate. This is because Pongo talar morphology reflects their extreme specialization for navigating arboreal environments as opposed to comparatively greater adoption of terrestrial locomotor strategies. Therefore, functional and possibly phylogenetic differences contribute to the separation between Pongo on the one hand and Pan, Gorilla, and H. sapiens on the other. This suggests that a more insightful interpretation of talar morphology in fossil hominins may benefit from a comparison which includes only the latter group (Kidd, 2004; Fleagle, 2013).

Consequently, in order to maximize the morphospace differences between Pan and Gorilla, and to generate a clearer distribution of the fossil hominins, Pongo was excluded from the analyses. This choice allows us to focus on a phylogenetically narrower interpretation of the appearance of human-like talar characteristics in the context of the origin of human bipedalism (Richmond et al., 2001).

In order to recognize talar traits that may be associated with different functions linked to locomotor behaviors (i.e. human form linked to obligate bipedalism and African ape form linked mostly to 
arboreal/terrestrial quadrupedalism), African apes were compared with a broad sample of $H$. sapiens (Sorrentino et al., 2019), including individuals characterized by different levels of mobility and subsistence strategies (e.g., highly mobile hunter-gatherers, sedentary farmers and postindustrial individuals). Moreover, the extant sample includes both female and male individuals to account for sexual dimorphism that could reflect differences in substrate preference, as has been observed in Gorilla (Remis, 1995), although sex-based differences were not a specific focus in the current experimental design.

The $H$. sapiens sample in this study is $100 \%$ terrestrial, whereas both Pan and Gorilla spend more than $85 \%$ of their time moving as terrestrial quadrupeds (Doran, 1996). Relative to gorillas and modern humans, common chimpanzees (Pan troglodytes) are the most arboreal (from about 8 to 18\% of arboreal locomotion) (Doran, 1993, 1996; Carlson, 2005). Lowland gorillas (which represent the Gorilla sample in this study), on the other hand, are the most terrestrial among the considered non-human apes. They spend from about 90 to $97 \%$ of their time in terrestrial settings. More specifically, female G. gorilla tend to overlap with chimpanzees (especially male chimpanzees) in the amount of time spent in arboreal environments (which translates into about $9 \%$ of total arboreal locomotion), while male G. gorilla are more terrestrial than both female gorillas and male chimpanzees. They spend only about $2 \%$ of their time moving on trees (Remis, 1995 , 1999; Doran, 1996; Doran and McNeilage, 1998; Carlson, 2005).

Therefore, contextualizing functional or behavioral implications for most of the available fossil hominin tali relied heavily on the morphological and behavioral differences exhibited between African apes and modern humans. In this study we considered left tali when present, otherwise right tali were mirrored and analyzed when substitution was necessary. Original bones or casts (e.g., fossils) were subjected to computed tomography (CT), microCT or laser scanning to generate 3D surface models. The modern human samples of Italian Medieval (Guidizzolo, North Italy) and Renaissance (Roccapelago) periods (voxel size: $0.470 \times 0.470 \times 0.6 \mathrm{~mm}$ ), as well as the 20th century individuals from the Frassetto Collection, i.e. the samples from Bologna (Belcastro et al., 2017) (voxel size: $0.960 \times 0.960 \times 0.7 \mathrm{~mm}$ ) and Nguni (voxel size: $0.976 \times 0.976 \times 0.5 \mathrm{~mm}$ ), were scanned with medical CT at the Department of Diagnostic Imaging of Santa Maria delle Croci 
Hospital in Ravenna (Italy). Tali from the Norris Farms \#36 collection (Late Prehistoric North America, 1300 A.D.) were scanned on the OMNI-X HD600 industrial microCT system at the Penn State Center for Quantitative Imaging. Data were collected with energy settings of $180 \mathrm{kV}$ and 0.11 $\mathrm{mA}$, inline pixel sizes of $0.048 \mathrm{~mm}$, and slice thickness and spacing of $0.051 \mathrm{~mm}$. Threedimensional surface reconstructions were made from the CT data using Avizo 9.0 (Visualization Science Group).

The Upper Palaeolithic sample from Italy (Romito 7, Romito 8, Romito 9 and Veneri 2) was surface scanned at the Department of Cultural Heritage with a 3D ARTEC scanner.

Casts of the Late Stone Age talus of Clark Howell Omo (Omo deposits, Ethiopia), as well as Native American (California, Shell Midden Cultures, 1500 B.C. - 500 A.D.), Gorilla and Pan samples, and hominin fossil casts of EM3519 and SPB4 (H. neanderthalensis), A.L. 288-1 (A. afarensis), OH 8 talus (H. habilis / P. boisei?), and Koobi Fora specimens KNM-ER 1464 and KNM-ER 1476 (Homo sp. / P. boisei?) from the Natural History Museum of London (Palaeontology department collection) were scanned with a Konica Minolta Vivid 910 surface laser scanner $(X: \pm 0.22 \mathrm{~mm}, \mathrm{Y}: \pm 0.16 \mathrm{~mm}$, $Z: \pm 0.10 \mathrm{~mm})$. Surface scan data were processed using the scanner’s associated software (Polygon Editing Tool, Konica Minolta, 2006) and Geomagic Studio 8 (3D Systems). Fossils casts of KNM-ER 813 (Homo sp.) and KNM-ER 5428 (H. erectus) were scanned with an Artec Spider (Artec 3D). Scan parameters and protocols for StW 88, StW 363, StW 486, and TM 1517 were reported by Su and Carlson (Su and Carlson, 2017). The Malapa talus was generated from high resolution CT data with energy settings of $130 \mathrm{kV}$ and $390 \mathrm{uA}, 4000$ projections, isotropic voxel dimensions of $0.0571 \mathrm{~mm}$ and $1.2 \mathrm{~mm}$ of copper was used to prefilter the beam hardening setting (DeSilva et al., 2018b).

LB1-15 (H. floresiensis) was scanned using a NextEngine 3D Scanner (macro setting, 16 scans per orientation, minimum two orientations per bone). Triangular meshes of the bone were created in ScanStudio HD PRO software and then aligned and merged in Geomagic Studio software. CT data of the Dmanisi talus (D4110) were acquired in the Department of Computed Tomography, Research Institute of Clinical Medicine (Todua Clinic) using a Siemens Somatom Sensation 64 medical CT scanner. The Spine Routine protocol was used for image acquisition. Relevant scan 
parameters for this fossil include: $120 \mathrm{kVp}$, a tube exposure time of $750 \mathrm{~ms}$, a slice thickness of $1.00 \mathrm{~mm}$, and a reconstruction increment of $0.4 \mathrm{~mm}$. Subsequent to the acquisition of these raw data, image data were reconstructed as 16-bit signed DICOM images using a bone reconstruction algorithm (i.e. a "B60s" Convolution kernel). A 3D model was reconstructed using a -200 threshold gray value. Virtual models of $H$. naledi tali (U.W. 101-148/149 and U.W. 101-1417) are from www.morphosource.org.

CT data of Krapina 235 were obtained from the NESPOS (Neanderthal Studies Professional Online Service) Database (voxel size: $0.154 \times 0.154 \times 0.4 \mathrm{~mm}$ ).

CT data of La Ferrassie 1 (voxel size: $0.219 \times 0.219 \times 0.4 \mathrm{~mm}$ ) and La Ferrassie 2 (voxel size: $0.251 \times 0.251 \times 0.5 \mathrm{~mm}$ ) were kindly provided by the Museum National d'Histoire Naturelle, Département Hommes, Natures, Sociétés, Paris. Digital three-dimensional (3D) models were virtually obtained by generating isosurface reconstructions in Avizo 9.0.

\subsection{Landmark and semi-landmark data}

A 3D-template of 15 anatomically homologous landmarks, 105 curve semi-landmarks and 131 surface semi-landmarks was created in Viewbox 4 software on a specimen of the Roccapelago modern human group (Fig.1, Table 1) (Sorrentino et al., 2019). All semi-landmarks were chosen to best represent the entire morphology of the talus as well as to allow extrapolation of the talar articular facets (i.e., the navicular facet, anterior and medial calcaneal facets, the trochlea, the posterior calcaneal facet, the medial malleolar facet, and the lateral malleolar facet) and combined facets (i.e., the trochlea and navicular facet; the posterior calcaneal and navicular facets; the posterior calcaneal facet and trochlea; the trochlea, posterior calcaneal and navicular facets; the trochlea and lateral malleolar facet; the trochlea and medial malleolar facet; the trochlea, lateral and medial malleolar facets; the trochlea, posterior calcaneal, lateral and medial malleolar facets). Beside the whole talus, we decided to analyze individual and combined facets to attempt to 
disentangle subtle morphological differences (i.e., size, shape, degree of curvature and orientation) in our hominin sample.

The 15 anatomically homologous landmarks and homologous curves were digitized across all specimens. Next, the semi-landmark configuration of the template was projected to targets, allowing semi-landmarks to slide on curves (curves semi-landmarks) and on the surface (surface semi-landmarks) in order to minimize the thin-plate spline (TPS) bending energy between the target and the template (Slice, 2006; Gunz and Mitteroecker, 2013). As a result, semi-landmarks can be considered geometrically homologous.

\subsection{Fragmentary fossils and semi-landmark estimation procedure}

Digital reconstructions were used to estimate missing regions of partially damaged fossils using TPS interpolation functions in Viewbox 4 software (Benazzi et al., 2011; Gunz and Mitteroecker, 2013).

Reconstruction was performed for the whole talus, or for individual/combined facets (SOM Table S3), in order to include as many fossils as possible in each analysis (i.e., analyses for the whole talus and for individual and combined facets).

Reliability of an individual reconstruction was tested by comparing the reconstruction based on the grand mean (mean of the entire extant sample) against reconstructions obtained by using the mean of Gorilla, Pan and H. sapiens, respectively (Fig. 2). If differences were observed (i.e., if the reconstructions fell in different areas of the PCA plots), then the reference choice was determined to have affected the final outcome and the fossil was removed from subsequent analysis. For example, this was the case with KNM-ER 813 (Homo sp.) in the analysis of the posterior calcaneal facet and for the combined posterior calcaneal facet and trochlea analysis, as well as for StW 486 ( $A$. africanus) in the analysis of the medial malleolar facet. Otherwise, if the reference choice did not affect results, the reconstruction based on the grand mean was used for analyses. The only exception to this protocol was with respect to Krapina 235 ( $H$. neanderthalensis), which was reconstructed using the $H$. sapiens mean. 


\subsection{Geometric morphometrics and statistical analyses}

The semi-landmark coordinates were allowed to slide against recursive updates of the Procrustes consensus and converted into shape coordinates by means of Generalized Procrustes Analysis (GPA) (Slice, 2006). Separate GPAs of the raw coordinates of the whole talus, as well as of each separate talar facet and multiple combinations of talar facets were performed. To consider the coevolution of size and shape across the extant taxa (i.e., evolutionary allometry), we performed a Procrustes form space analysis by adding the natural logarithm of centroid size (InCS) as an additional variable to Procrustes shape coordinates (Mitteroecker et al., 2013; Klingenberg, 2016). Shape and form space PCAs were calculated using Procrustes coordinates of the extant sample, while fossil specimens were projected into this space to evaluate their morphological variation in relation to Pan, Gorilla and $H$. sapiens.

Differences among extant group means ( $H$. sapiens, Pan, Gorilla) were evaluated for the first three PCs through ANOVA, while a Tukey's post hoc test was used to identify interspecific differences (Shaw and Ryan, 2012) (SOM Table S4).

Allometric shape variation was first investigated by the Pearson product-moment correlation coefficient ( $r$ ) of shape variables (PCs) against InCS. This analysis aims to identify size-related morphological variation among $H$. sapiens and African apes. Centroid size of hominoid tali can be used as a proxy of body mass, however, this approach can be problematic when humans are included in the sample as talar centroid size can overestimate $H$. sapiens body mass (Parr et al., 2011a,b;; Parr et al., 2014). Thus, in this work we will consider talar centroid size as a proxy for overall talar size.

Furthermore, angles between (evolutionary) allometric trajectories of African ape taxa and $H$. sapiens were computed in form space PCA to test the null hypothesis of shared allometric trajectories among extant taxa, and a permutation test $(n=1000)$ was used to assess the statistical significance of these trajectory angles (Bailey et al., 2014). This analysis assesses 
covariation of size and shape in the talus of extant taxa, and determines if change in size led to convergent, parallel or divergent shape among taxa (Mitteroecker et al., 2013).

The degree of morphological integration between an individual facet and the rest of the talar configuration was evaluated while accounting for phylogenetic relationships among extant taxa (Adams and Felice, 2014). We used a majority rule consensus tree obtained from ten equally parsimonious trees, all of which can be freely downloaded from the $10 \mathrm{kTrees}$ website following the link http://10kTrees.fas.harvard.edu (Arnold et al., 2010). The tree was rooted and identified G. gorilla as the outgroup. Shape data were previously aligned using Generalized Procrustes Analysis (GPA). Next, morphological covariation was statistically assessed permuting data per 1000 iterations. We assumed that each individual talar structure is strongly correlated with overall talar shape since the talus acts like a modulus.

Further analyses were performed to investigate some specific findings of the present work. For trochlea and combined trochlea and medial malleolar facet analyses, three $A$. africanus specimens (StW 88, StW 363 and StW 486) were included. Phenetic distance analysis was performed to test the hypothesis that $A$. africanus variability is greater than variability observed in the extant groups. Phenetic distance among $A$. africanus $(\mathrm{K}=3)$ was compared against phenetic distance based on random resampling of $K$ subsamples (permutation test $n=1000$ ) of each extant sample $\left(\mathrm{S}_{\mathrm{i}, \mathrm{k}}\right)$. Then, statistical significance $(p=<0.05)$ was assigned if the phenetic distance of $A$. africanus $\left(\mathrm{S}_{0, \mathrm{k}}\right)$ was greater than or equal to $95 \%(N+/ N>95 \%)$ of the resampled distances (Lordkipanidze et al., 2013). Moreover, we compared phenetic distance of the other three australopiths $\left(\mathrm{S}_{0, \mathrm{k}}\right)$ in our sample (A.L. 288-1, U.W. 88-98, TM1517) with those of the extant sample and those of the three tali that have been attributed to $A$. africanus. We tested the hypothesis that some $A$. africanus tali could have an erroneous taxonomic designation, as another species has been suggested as present at Sterkfontein (Clarke, 2013) and Su and Carlson (2017) suggested the possibility of two different 'morphs' based on internal talar structure (i.e., trabecular properties). Figure 10 and SOM Figure S6 show histograms depicting shape distances in extant taxa, A. africanus (StW 88, StW 363 and StW 486) and the Australopithecus/Paranthropus group (A.L. 288-1, U.W. 88-98, TM1517). 
Data processing and analysis routines were written in R software ( $R$ Core Team, 2017) using the R packages "geomorph" (Adams and Otárola-Castillo, 2013) and "Morpho" (Schlager, 2017).

\section{Results}

\subsection{Whole talus}

The first three PCs in shape space describe $47.6 \%$ of the total variance (Fig. $3 a$ and 4). Talar shape scores on PC1 (34.7\%) are significantly different between African apes and $H$. sapiens $($ ANOVA, Df $=2, F$-test $=618, p=<0.001$, SOM Table S4). Shape parameters captured by PC1 were significantly related to size $(p=<0.001)$, but were likely not solely due to the effects of size $(r=0.4535)$. Individuals yielding positive scores on PC1 (i.e., $H$. sapiens) display a taller talar body with an inclined and laterally wider head, a flatter navicular facet, a shorter neck, a more squared and flatter trochlea, a flatter posterior calcaneal facet, more vertical orientation of the lateral malleolar facet, a flatter medial malleolar facet, and a more vertical flexor hallucis longus (FHL) groove. Individuals with negative PC1 scores (i.e., African apes) exhibit shorter talar bodies, a more dorsally extended articular surface of the talar head, rounder navicular facets, more elongated necks, more posteriorly narrowed and grooved trochleae with dorsally elevated lateral margins, more concave posterior calcaneal facets, more flared lateral malleolar facets, more cupped and distally elongated medial malleolar facets, and more oblique and deeper FHL grooves (Fig. 3c).

PC2 (7.1\%) separates Gorilla from Pan (ANOVA, Df $=2$, F-test $=66.97, p=<0.001$, SOM Table S4). Positive scores (i.e., Gorilla) indicate a shorter talar body, smaller and flatter navicular facets, which are also mediolaterally extended, more symmetrical and trapezoidal trochleae with less deep central grooves and more dorsally elevated lateral margins and less concave posterior calcaneal facets. Negative scores (i.e., Pan) are related to relatively taller corpora in respect to positive 
scores (i.e., Gorilla), a rounder and larger navicular facet, a more oblique trochlear axis relative to the head, a more grooved trochlea with equally elevated lateral and medial margins, and a more distally elongated medial facet and a deeper posterior calcaneal facet (Fig. 3c). PC3 (5.8\%) significantly differentiates Pan and $H$. sapiens (ANOVA, Df $=2$, F-test $=3.773, p=0.0254$; SOM Table S4), with the latter showing a shorter and wider talus (Fig. 3c). For some talar characteristics H. sapiens and Gorilla are more similar to one another than are $H$. sapiens and Pan, especially concerning the curvature of the navicular facet, and the shape of the trochlea and posterior calcaneal facet.

Among the fossils, australopiths are generally more similar to African apes, while fossil Homo specimens are closer to $H$. sapiens. In accordance with previous work on talar external features (Harcourt-Smith and Aiello, 2004; DeSilva, 2009; Zipfel et al., 2011; Prang, 2015; Prang, 2016a), australopiths show a mosaic of ape-like and human-like talar features and some fossils show a greater mixture of features than others (e.g., compare StW 88 and the A. sediba talus) (Fig. 3a), such as an ape-like long neck and a concave posterior calcaneal facet, and, at the same time, a less flared lateral malleolus facet and a more vertical FHL groove. Homo habilis $(\mathrm{OH} 8)$ and D4110 (Dmanisi) plot between $H$. sapiens and African apes in PC1, suggesting that some primitive features are still present in these early Homo specimens, but the two fossils are separated along PC2. The talus of $\mathrm{OH} 8$ shows a deep, central, grooved trochlea and elevated lateral margin, suggesting an arcuate ape-like path of the leg during the stance phase. Even if the Dmanisi talus shares some features with modern human tali (e.g., relatively flat trochlea, inclined head, and no cup-shaped medial malleolus), it exhibits other traits that are ape-like (e.g., an elongated neck and antero-posteriorly narrowed posterior calcaneal facet that is slightly more concave than in humans). The two $H$. naledi tali are quite different in shape from each other, as has been previously suggested (Harcourt-Smith et al., 2015). The U.W. 101-148/149 specimen plots close to $H$. habilis, probably due to its modestly grooved trochlea and relatively higher lateral rim and elongated neck. U.W. 101-1417, KNM-ER 1464, and LB1-15 cluster near the range of variation expressed by $H$. sapiens, while the Neandertal sample overlaps with the range exhibited by $H$. sapiens. 
In the form space PCA, the first three PCs explain $78.6 \%$ of total variance (Fig. 3b). PC1 (66.1\%) accounts for variation in overall size, separating Pan from Gorilla and H. sapiens. PC2 (10.2\%) differentiates African apes from $H$. sapiens, as previously described for shape space PC1 and PC2. PC3 (2.5\%) does not differentiate between African apes, $H$. sapiens, nor among fossil hominins. Homo sapiens and Pan have different (evolutionary) allometric trajectories ( $\alpha=20.9, p$ $==0.0049$; magnitude $p=<0.0069$ ), while no differences were found between $H$. sapiens and Gorilla. Pan and Gorilla also differ in their allometric trajectories $(\alpha=22.1, p=0.0069$; magnitude $p$ $=0.0079$ ). Except for $A$. africanus (StW 88), which plots inside the Pan range, all other australopiths and early Homo fall outside the ranges of both extant African apes and $H$. sapiens.

\subsection{Individual articular facets}

Morphological integration analysis reveals that the talar facets are highly integrated with the whole talus $(1$ to $0.981 ; p=<0.001$; iterations $=1000)$. However, distinct facets diversely discriminate between bipedal forms and arboreal/terrestrial quadrupedal forms. Specifically, morphology of the medial malleolar facet (SOM Section 1 and Fig. S2), anterior-medial calcaneal facet (SOM Section 1 and Fig. S3), posterior calcaneal facet, and trochlea tend to be more similar among extant taxa when comparing them to the navicular and lateral malleolar facets.

3.2.1 Navicular facet. For the navicular facet, the first three PCs account for $70 \%$ of morphological variation (Figs. 5a and 6). A significant positive correlation with InCS was found for PC1 ( $r=$ 0.4656, $p=<0.001)$, while significant negative correlations were observed for PC2 $(r=-0.1624, p$ $=0.0434)$ and PC3 $(r=-0.2626, p=<0.001)$. PC1 describes $44.4 \%$ of variation and distinguishes African apes from $H$. sapiens (ANOVA, Df $=2$, F-test $=190, p=<0.001$, SOM Table S4) by discriminating the rounded and dorsally extended navicular facet typical of African apes from the flared and laterally expanded navicular facet of $H$. sapiens (Fig. 5b). While all extinct Homo specimens, except possibly KNM-ER 1464, fall inside or at the edge of the modern human range of 
variation, australopiths (StW 88 and U.W. 88-98) are adjacent to African apes except for A.L. 288-1 (A. afarensis), which plots perfectly within the $H$. sapiens range.

PC2 (ANOVA, Df $=2, F$-test $=2.975, p=0.0543$ ) does not discriminate among extant taxa, while PC3 (ANOVA, Df $=2$, F-test $=31.34, p=<0.001$ ) significantly differentiates Gorilla and H. sapiens from Pan (SOM Table S4). Specifically, positive values along PC3 are associated with tali exhibiting rounded, spherical navicular facets and negative values along PC3 are associated with tali exhibiting flatter, rectangular navicular facets.

In form space, the first three PCs describe $81.9 \%$ of variation (Fig. 5c). PC1 (62\%) tends to separate Gorilla and $H$. sapiens from Pan, while PC2 distinguishes between African apes as a group and H. sapiens. Most of the small hominins (U.W 88-98, StW88, KNM-ER 1464, LB1-15) plot close to the Pan range, except for A.L. 288-1 (A. afarensis), which follows the $H$. sapiens allometric trajectory (Fig. 5c). No differences in angles of trajectories have been found among extant taxa. Pan and $H$. sapiens significantly differ only in allometric magnitude of trajectories ( $p=$ 0.0039), as do Gorilla and Pan ( $p=0.0349)$.

3.2.2 Lateral malleolar facet. The shape space 3D PCA plot for the lateral malleolar facet depicts a trend separating bipedal species from relatively arboreal species (Figs. 7a and 8). There are significant differences between African apes and $H$. sapiens on PC1 (29\%; ANOVA, Df $=2, F$ test $=35.81, p=<0.001$, SOM Table S4) and PC2 (21.3\%; ANOVA, Df $=2, F$-test $=49.64, p$ $=<0.001$, SOM Table S4), which is correlated with InCS $(r=0.2757, p=0.0004)$, while PC3 $(9.8 \% ;$ ANOVA, Df $=2, F$-test $=5.032, p=0.0077$, SOM Table S4) accounts for differences only between Pan and Gorilla. Most of the fossil hominins (i.e., A.L. 288-1, U.W. 88-98, D4110) tend to plot within or closer to the modern human range, and only KNM-ER 1464 (Homo sp./ $P$. bosei) falls inside the area of overlap between Gorilla and $H$. sapiens. Distally extended and concave lateral malleolar facets yielded negative scores on PC1, while inferior-superiorly larger and flatter lateral malleolar surfaces return positive scores (Fig. 7c). Morphology along PC2 displays a lateral malleolar facet with the inferior apex distally extended in negative scores and 
plantarly extended in positive scores. Negative scores on PC3 are associated with a smaller facet and an extension of the inferior apex compared to a larger facet and shorter apex along positive scores on PC3.

The first three form space PCs explain $77 \%$ of variance (Fig. $7 b)$. PC1 (54.8\%) separates $H$. sapiens and Gorilla from Pan, while both PC2 (13.5\%) and PC3 (8.7\%) show overlap among extant taxa, mainly between Gorilla and $H$. sapiens. Fossil hominins are characterized by a high degree of variability in form space. Only Gorilla and $H$. sapiens significantly differ in allometric trajectories ( $\alpha=18.5, p=0.0179)$, which converge with increasing talar size (Fig. 7b).

3.2.3 Trochlea. Shape space PC1 (31.9\%) accounts for significant differences among the extant groups (ANOVA, Df $=2$, F-test $=137.1, p=<0.001$, SOM Table S4) despite their partial overlap (Fig. 9a,d,e). Positive PC1 values reflect a flatter, wider, and more squared trochlea, typical of $H$. sapiens, while negative values reflect a grooved, narrowed, and more trapezoidal trochlea with an elevated lateral rim that is typical of African apes (Fig. 9c). The larger trochlear surface in $H$. sapiens positively correlates with InCS on PC1 $(r=0.2257, p=0.0039)$, while the correlation is negative for PC2 $(r=-0.4086, p=<0.001)$ and PC3 $(r=-0.1533, p=0.0521)$. PC2 (12.6\%; ANOVA, Df $=2, F$-test $=45.46, p=<0.001)$ and PC3 (10\%; ANOVA, Df $=2, F-$ test $=11.57, p=<0.001)$ mainly reflect differences between more trapezoidal trochlea in negative scores and more rectangular trochlea in positive scores.

In the shape space PCA, extinct Homo tend to fall within $H$. sapiens variability (except for a Neandertal specimen, Krapina 235), while australopiths tend to plot around the area of overlap between Pan and $H$. sapiens. Nevertheless, two of the three $A$. africanus tali (StW 363 and StW 486) fall securely within the $H$. sapiens range of variability. Considering the variability in shape space exhibited by the three specimens attributed to $A$. africanus (StW 363, StW 486, StW 88), we test the hypothesis that phenetic distance measured across samples of $A$. africanus is larger than that measured in extant taxa (see Methods), suggesting the presence of multiple species among individuals currently attributed to $A$. africanus (Clarke, 2013; Su and Carlson, 2017). Phenetic 
distances (Fig. 10) between specimens of $A$. africanus are significantly larger than those measured among 1000 re-sampled $H$. sapiens $(p=<0.05)$, whereas the phenetic distance exhibited by a group comprised of A.L. 288-1 (A. afarensis), U.W. 88-98 (A. sediba) and TM1517 (P. robustus) does not differ from that of $H$. sapiens. However, no significant difference was observed when comparing $A$. africanus to Pan and borderline non-significance was observed when compared to Gorilla.

Form space analysis (Fig. 9b) reveals that PC1 (63.2\%) separates larger-trochlea forms $(H$. sapiens and Gorilla) from the smaller-trochlea form of Pan, while PC2 (11.6\%) and PC3 (4.2\%) tend to separate both African ape taxa from $H$. sapiens. Allometric trajectories differ between Pan and $H$. sapiens ( $\alpha=16.9, p=0.0199$; magnitude $p=0.0089$ ), as well as between Pan and Gorilla ( $\alpha=26.1, p=0.0019$; magnitude $p=0.0069$ ). Fossil hominins with lower centroid size (i.e., A.L. 288-1, StW 88, StW 363, StW 486, U.W. 88-98, TM 1517, OH 8, LB1-15, U.W. 101-1417, U.W. 101-148/149) fall closer to the smaller-trochlea Pan and both groups tend to exhibit greater similarities to smaller-trochlea $H$. sapiens. On the other hand, fossil hominins with higher centroid size fall within the $H$. sapiens range.

3.2.4 Posterior calcaneal facet. The first three shape-space PCs of the posterior calcaneal facet account for $56.6 \%$ of overall variance (Fig. 11a,d,e). PC1 (30\%) tends to separate African apes from $H$. sapiens (ANOVA, Df $=2$, F-test $=270.9, p=<0.001$, SOM Table S4). Fossil hominins show high variability and share morphological affinities with both African apes and $H$. sapiens. No relevant differences were recorded between Australopithecus and extinct Homo (for example some Neandertals fall inside the African ape range together with some australopiths). Moving from the PC1 positive extreme to the PC1 negative extreme (Fig. 11c), shape changes from a less concave calcaneal facet to a more concave and rectangular-shaped facet. PC2 (15.8\%) separates Gorilla and $H$. sapiens from Pan (ANOVA, Df $=2, F$-test $=7.9, p=0.0005$, SOM Table S4). PC2 exhibits a broad and flatter calcaneal facet in the negative direction and a more concave and antero-posterior shorter calcaneal facet in the positive direction. PC3 (10.8\%) 
accounts for significant differences among the extant taxa (ANOVA, Df $=2, F$-test $=34, p=$ $<0.001$, SOM Table S4), discriminating a more oval and relatively flatter facet on the positive extreme from a more rectangular and concave form on the negative extreme. All three PCs positively correlate with InCS (PC1, $r=0.4416, p=<0.001 ; \mathrm{PC} 2, r=-0.2715, p=0.0005$; PC3, $r=0.1990, p=0.0121)$.

In form space, the three PCs explain $80.3 \%$ of overall variance (Fig. 11b). All three extant taxa show parallel allometric trajectories without any significant differences in angles and magnitude. As it was observed in shape space PCA, fossil hominins share posterior calcaneal features linked to size and shape with both African apes and H. sapiens.

\subsection{Combined facets}

Talar articular structures were explored combining the facets involved in the talocrural, subtalar and transverse tarsal joints (SOM Section 2 and Figs. S4-S11). General results of combined facets return a clearer separation between African apes and humans than analyses of individual facets, suggesting that angles, proportions and relative positions of facets play a fundamental role in distinguishing bipedal forms. The combination of the three major articular surfaces of the talus (i.e., $\mathrm{X}, \mathrm{Y}$, and $\mathrm{Z}$ ) is particularly informative in this regard.

3.3.1 Combined trochlea, navicular and posterior calcaneal facets. The combination of the trochlea, navicular and posterior calcaneal facets provides the best results in terms of separation between australopiths and Homo specimens. The first three PCs in shape space account for $49.5 \%$ of the observed variation among extant taxa (Figs. 12a and 13). PC1 (36.6\%) provides significant differences between $H$. sapiens and African apes (ANOVA, Df $=2, F$-test $=613.8, p=$ $<0.001$; SOM Table S4). Homo sapiens is characterized by a plantodistally oriented navicular facet relative to a taller talar corpus, which increases the distance of the tibiotalar joint (i.e., the ankle joint) from the ground (Fig. 12c). Australopiths are generally more similar to African apes, while most fossil Homo specimens are closer to $H$. sapiens, with Neandertals falling within the 
range for $H$. sapiens. PC2 (7\%) accounts for differences among all three extant groups $($ ANOVA, Df $=2$, F-test $=10.9, p=<0.001$, SOM Table S4), whereas PC3 $(5.9 \%)$ separates Pan on one side from Gorilla and $H$. sapiens on the other (ANOVA, Df $=2, F$-test $=18.2, p=$ $<0.001$, SOM Table S4). In the first three PCs, shape correlates with $\operatorname{lnCS}(\mathrm{PC} 1, \mathrm{r}=0.4452, p=$ $<0.001 ; \mathrm{PC} 2, \mathrm{r}=0.2657, p=0.0008 ; \mathrm{PC} 3, \mathrm{r}=-0.22429, p=0.0023)$ and this relationship reflects enlarged articular surfaces in larger tali, which would theoretically lessen peak compressive forces through any one point in these joints. In form space (Fig. 12b), PCA shows similar results obtained in shape space, and no significant differences in allometric trajectories were found among extant taxa. Extinct Homo fall between $H$. sapiens and African apes, while australopiths are closer to Pan, and Neandertals fall within the range of $H$. sapiens variation.

\section{Discussion}

Results obtained for the whole talus (Figs. 3-4) are consistent with those of previous studies of talar external form, showing that differences in talar shape among extant hominins are probably due to different frequencies in habitual locomotor behaviors (bipedalism versus arboreal/terrestrial quadrupedalism) (Harcourt-Smith, 2002; Jungers et al., 2009; Turley and Frost, 2013; Parr et al., 2014; Harcourt-Smith et al., 2015; Prang, 2015). Among the extant taxa, Gorilla and H. sapiens share talar structural characteristics, especially flatter trochleae, less convex navicular facets and less concave posterior calcaneal facets that may reflect adaptations for more stability at talocrural, subtalar and midtarsal joints (Latimer et al., 1987; Turley and Frost, 2013; Prang, 2015; Prang, 2016b). More specifically, the above-mentioned talar features are shared by $H$. sapiens and mountain gorillas, while the latter also exhibit differences when compared against more arboreal lowland gorillas. This suggests that flatter trochleae, less convex navicular facets and less concave posterior calcaneal facets may result from functional requirements specifically attributed to terrestrial substrates (Dunn et al., 2014; Knigge et al., 2015). Others have previously shown that talar morphology is influenced by size and substrate preference, therefore the talar features shared 
by Gorilla and $H$. sapiens may indicate that relatively larger individuals exhibit a talar morphology that is more stable on terrestrial substrates, relative to smaller and more arboreal taxa (i.e., Pan) (Remis, 1995; Turley and Frost, 2013; Knigge et al., 2015). Heavier body weight is likely to increase peak force at the talocrural joint both during terrestrial bipedal locomotion and terrestrial quadrupedalism, causing flattening of the articular surface with the consequent loss of talocrural joint mobility (Latimer et al., 1987).

In contrast with some recent analyses of the hominin talus (Harcourt-Smith, 2002; Jungers et al., 2009; Harcourt-Smith et al., 2015), our results show that no fossil hominins sampled here fall within the African ape range when whole talar morphology is considered in shape space (Figs. 3-4). This is argued to reflect their own unique combination of morphological features, likely reflecting their also unique combination of locomotor modes that is not entirely ape-like (Harcourt-Smith and Aiello, 2004; Haile-Selassie et al., 2012; Holowka and Lieberman, 2018; McNutt et al., 2018). In addition, neither A.L. 288-1 (A. afarensis) nor KNM-ER 1464 (Homo or P. boisel) fall within the $H$. sapiens range, while the talus LB1-15 attributed to $H$. floresiensis (one of the geologically youngest species of genus Homo) plots closer to $H$. sapiens in shape space than has been suggested elsewhere (Jungers et al., 2009; Harcourt-Smith et al., 2015). OH 8 (potentially H. habilis) and D4110 (Dmanisi) exhibit a mosaic of human-like and ape-like talar features. Since the fossil remains from Dmanisi are attributed to $H$. erectus, this suggests that early Eurasian Homo still retained primitive features in the foot despite an apparent structural capacity for sustained longdistance walking (Harcourt-Smith and Aiello, 2004; Pontzer, 2012; Dowdeswell et al., 2017). In contrast with previous results (Rosas et al., 2017), Neandertals are generally similar to our $H$. sapiens sample, which was specifically selected to account for diversity in subsistence strategies, locomotor activity, landscape use, and chronology (Sorrentino et al., 2019). Individual facets have varying potential to distinguish features associated with bipedal locomotion from other forms of habitual locomotion. For example, the medial malleolar facet and the anteriormedial calcaneal facet (SOM Section 1 and Figs. S2-3) show considerable overlap in shape space between African ape and $H$. sapiens clusters, suggesting that the shape of these two facets cannot be considered individually as markers of derived bipedal features. Similarly, although to a lesser 
extent, African ape and $H$. sapiens clusters tend to overlap in shape space when considering the morphology of the posterior calcaneal facet and trochlea, respectively.

The latter overlap in shape space is quite unexpected (Fig. 9), as external morphology of the trochlea is commonly considered an indicator of function and locomotor behavior in hominins (Latimer et al., 1987; Aiello and Dean, 1990; Harcourt-Smith, 2004; Dunn et al., 2014; DeSilva et al., 2019). H. sapiens show a flatter, wider, and more squared-off trochlea with equally elevated rims (Fig. 9c). It has been argued that this configuration reflects the way in which the leg passes over the foot during stance phase in bipeds (i.e., a relatively straight path) in juxtaposition to that exhibited by knuckle-walkers (i.e., a relatively arcuate path), and likely overall positional behavior differences incorporating more flexed lower limb joints and a more dorsiflexed ankle in African apes even during quadrupedalism compared to the more extended limb postures of modern humans (Aiello and Dean, 1990; Harcourt-Smith, 2002; Harcourt-Smith and Aiello, 2004; Turley and Frost, 2014; O'Neill et al., 2015; Finestone et al., 2018). However, our results suggest that the morphology of the hominin trochlea could be over-interpreted in terms of functional and behavioral adaptation. This conclusion is supported by recent work on external morphology of the proximal and distal tibia suggesting that the form of the distal tibia is not unequivocally linked to obligate bipedal locomotion (Frelat et al., 2017). Since the trochlea is primarily involved in the transfer of weight across the ankle joint towards the ground, size can greatly impact external morphology of the trochlea in hominins, to the extent that smaller and larger shapes converge in extant species (Fig. 9b). However, we do not completely rule out that the trochlea could be an indicator of behavioral locomotor adaptation, as recent work on internal structure of the trochlea has shown differences among apes especially in the anterior-medial subregion that may be linked to different locomotor foot kinematics (Su and Carlson, 2017). Thus, studying external and internal forms using the same tali may be the future direction for testing what signals are related to functional and behavioural locomotor adaptation. In accordance with previous results on the shape of major articular surfaces of the subtalar joints, our results on the posterior calcaneal facet (Fig. 11) show a trend from a more concave and rectangular shape in African apes to a less concave shape in $H$. sapiens. This difference has been 
interpreted as an expression of different ranges of inversion and eversion capability at the subtalar joint in hominins, among which $H$. sapiens show reduced subtalar joint motion to achieve increased stability at the ankle during bipedal gait (Harcourt-Smith, 2004; Zipfel et al., 2011; Turley and Frost, 2013; Knigge et al., 2015; Prang, 2016a; DeSilva et al., 2019). Our results, however, show that fossil hominins -- even those commonly recognized as fully bipedal -- share external posterior calcaneal features with both African apes and $H$. sapiens, thus suggesting that caution should be applied when using external form of the posterior calcaneal facet for interpreting locomotor behavior of extinct hominins.

Overall, we show that fossil hominins exhibit a broad range of variation in the above-mentioned facets, suggesting evolutionary complexity in the timing of the acquisition of modern human-like external form for these facets. Among the individual facets of the talus, the most diagnostic morphologies in the talus for discriminating habitual bipedal forms from habitual arboreal/terrestrial quadrupedal forms are the navicular and lateral malleolar facets. Considering additional external morphologies (as seen in shape space analyses) of the medial malleolar facet, anterior-medial calcaneal facet, posterior calcaneal facet, and trochlea are less informative for inferring locomotor behaviors, but integrating additional other parameters, such as orientation and angular relationship with the rest of the talar configuration, can be beneficial for recognizing bipedal features even in these facets (Latimer et al., 1987; DeSilva, 2009; Lovejoy et al., 2009; Prang, 2015; Prang, 2016a). The navicular facet best distinguishes $H$. sapiens from African apes. The former is characterized by a flared and laterally expanded navicular facet (Fig. 5). It has been argued that the navicular facet is a key element for enhancing stability of the midtarsal region, as decreasing curvature of the navicular facet together with torsion of the talar head may represent a derived feature associated with modern human toe-off (Elftman and Manter, 1935; Lamy, 1986; Aiello and Dean, 1990; Harcourt-Smith, 2002; DeSilva, 2010; Turley and Frost, 2013; Parr et al., 2014; Harcourt-Smith et al., 2015; Prang, 2016a,b). However, experimental data have indicated that the overall range of midfoot joint mobility during stance phase is greater in humans than chimpanzees and these groups also share similar passive ranges of motion at midfoot joints (Greiner and Ball, 2014; Holowka et al., 2017a). Therefore, Holowka and colleagues (2017a) have suggested that differences in midfoot joint morphology could 
be related to "greater foot stiffness and power generated during push off in bipedal walking" rather than reflecting a loss of midfoot mobility in humans (i.e., stability). Others have noted flatter talar heads in mountain gorillas than in lowland gorillas, suggesting an association of this feature with more terrestrial behavior (Knigge et al., 2015).

Our results indicate that most fossil hominin tali exhibit modern human-like navicular morphology, including that of $A$. afarensis. This suggests that $A$. afarensis could have had a stiffer medial midtarsal region concomitant with the loss of the midtarsal break that is more typical of non-human great apes (DeSilva, 2010; Nowak et al., 2010; Raichlen et al., 2010; Ward et al., 2011; Parr et al., 2014; Prang, 2015; Prang, 2016a; but see Crompton et al., 2012; DeSilva et al., 2015). The majority of evidence suggests that the medial column of the foot may have evolved more recently in the human evolutionary lineage, emerging after the earlier adaptive modification of a modern humanlike lateral column of the foot (Kidd, 1999; Lovejoy et al., 2009; Ward et al., 2011; Fernández et al., 2018; McNutt et al., 2018), even if some evidence suggests that the evolutionary trajectory of the lateral column is not so simple (Dowdeswell et al., 2017). Here, the talonavicular joint of $A$. afarensis appears to reveal increasing relative stiffness in the medial column by at least 3.2 million years ago. Australopithecus africanus and A. sediba (but see DeSilva, 2010 for an alternative view), however, retain a navicular surface morphology more similar to that of African apes, and specifically to that of Gorilla (Prang, 2016a,b). This may support the hypothesis that $A$. africanus and $A$. sediba may have exhibited less stiff talonavicular joints during push off and a more ape-like weight transfer from the lateral hindfoot to the medial midfoot during the last half of stance phase (Su and Carlson, 2017). Size correlation with the first three PCs could be related to transmission of body weight from the talar head through the navicular, and ultimately to the first ray at toe-off (Griffin et al., 2010; Jashashvili et al., 2015). Indeed, even if the navicular facet of $A$. afarensis is smaller compared to those of $H$. sapiens, its morphology follows the $H$. sapiens allometric trajectory (Fig. $5 \mathrm{c}$ ). Thus, our results support the idea that external shape of the navicular facet of $A$. afarensis suggests that this hominin may have resembled modern humans in its propulsion mechanism during toe-off, and that this adaptation may have been maintained in at least some Homo specimens (Prang, 2016a). This is corroborated by the fact that $A$. afarensis is thought to have had a relatively more adducted hallux 
than other australopiths as confirmed by fossilized footprints at Laetoli, Tanzania, that seemingly indicate the absence of hallucal opposability (Latimer and Lovejoy, 1990; Bennett et al., 2009; Raichlen et al., 2010; Gill et al., 2015; Fernández et al., 2016; DeSilva et al., 2018a), a condition enabling the foot to act as a rigid lever in synergy with intrinsic foot musculature to accomplish effective push-off (Jashashvili et al., 2015; Holowka et al., 2017a; Holowka and Lieberman, 2018; Farris et al., 2019). In this respect the present study confirms what other studies have suggested in that the talo-navicular joint is a relevant target for comparing midfoot mobility in extinct hominins (Holowka et al., 2017a).

The lateral malleolar facet (Figs. 7 and 8), despite a slight overlap between H. sapiens and African apes, discriminates between fossil hominins and African apes with the exception of KNM-ER 1464, which falls in the specific area of overlap between Gorilla and $H$. sapiens. High concavity and greater lateral projection of the lateral malleolar facet in African apes (Fig. 7c) may contribute to maintaining joint congruence between the fibula and talus throughout the range of motion in arboreal and terrestrial environments.

It has been argued that the African ape foot is automatically inverted during dorsiflexion in arboreal environments (i.e., during climbing) and it has an inverted posture as a result of a varus knee during locomotion on flat surfaces (DeSilva, 2009; Turley and Frost, 2013; Su and Carlson, 2017; Wunderlich and Ischinger, 2017; Holowka et al., 2017b). This is proved by a recent kinematic study on chimpanzees (Holowka et al., 2017b) showing that they have an inverted ankle joint in all locomotor modes (climbing, terrestrial quadrupedalism, arboreal quadrupedalism) during and after touchdown, when their ankle joint is also dorsiflexed. The only exception consists of the first $25 \%$ of the stance phase in both quadrupedal modes, when the foot is instead everted (Holowka et al., 2017b). In contrast, the sole of the human foot is plantarly oriented in neutral position as a consequence of a valgus knee, allowing the knee and ankle to be directly under the center of gravity (Latimer et al., 1987; O’Neill et al., 2015). Therefore, different knee and ankle positions produce different force transmission through the ankle joint that ultimately may drive the evolution of the flaring morphology of the lateral malleolar facet in the talus of African apes (Latimer et al., 1987; Aiello and Dean, 1990; Harcourt-Smith, 2002; O'Neill et al., 2015; Su and Carlson, 2017). In 
fact, the laterally extended distal malleolar facet of the fibula has been attributed to greater load distribution and mobility (especially a greater degree of dorsiflexion in climbing activities) in African apes than in humans, as well as a general orientation of the fibula determined by a more adducted hind limb posture and larger peroneal musculature that helps to stabilize the African ape foot in arboreal locomotion (Barnett and Napier, 1952; Stern and Susman, 1983; Latimer et al., 1987; Aiello and Dean, 1990; Marchi, 2007, 2015). Gebo (1992) argued that the well-flaring fibular malleolar facet of African apes may reflect, among other traits (e.g., laterally rotated calcaneus, everted forefoot), a plantigrade heel-strike foot posture during terrestrial locomotion.

Our results show that fossil hominins fall within or close to the $H$. sapiens range while considering the lateral malleolar facet, while African apes overlap with one another and are distinguishable from humans, likely reflecting habitual bipedal versus non-bipedal foot postures during locomotion. Furthermore, it is possible that fossil hominins lack African ape-like talar lateral malleolar morphology likely as a consequence of decreasing habitual arboreality, reducing inverted posture of the foot, and increasing an emphasis on ankle stability, although more experimental data are needed to ultimately test these hypotheses. As argued by Gebo and Schwartz (2006), and corroborated by our results, the lateral malleolar facet does not distinguish australopiths from Homo. Indeed, the lateral malleolar facet seems to have evolved toward a bipedal form early within (or preceding) the australopith portion of the hominin lineage. This is in line with the work of DeSilva (2009), suggesting that the hominin ankle joint is poorly adapted to modern ape-like vertical climbing. Furthermore, recent studies by Venkataraman and colleagues (Venkataraman et al., 2013a,b) on habitually climbing modern human populations suggest that ankle traits related to facultative arborealism can be obscured by increased stabilization demands in terrestrial locomotion. Therefore, even if the potential for arboreality could be retained in the fossil hominin talus (Harcourt-Smith and Aiello, 2004; Preuschoft, 2004; DeSilva, 2009; Prang, 2016a), it could be obscured by the influence of habitual bipedal locomotion on the lateral malleolar facet of the talus. The combination of the trochlea, and the navicular and posterior calcaneal facets (Figs. 12 and 13) may suggest a unidirectional trend in the appearance of the medial longitudinal arch from the human-chimpanzee last common ancestor to $H$. sapiens. In $H$. sapiens, the trochlea is dorsally 
elevated with respect to the posterior calcaneal facet, resulting in a taller talar corpus, while the talar head is plantarly oriented (i.e., declined) (Fig. 12c). Following Prang (2015), Day and Wood (1968), and Gebo (1992), the relative arrangement of these talar facets might be a proxy for inferring the presence of a medial longitudinal arch, which is absent in African apes while it is present as a derived feature in the modern human foot. Evolution of the longitudinal arch is reflected by dorsal elevation of both the talus and calcaneus, as well as by re-orientation of the subtalar and transverse tarsal joints. Length and declination of the neck of the talus and the medial longitudinal arch are associated with a medial projection of the head relative to the talar corpus, which all facilitate an effective toe off (Day and Wood, 1968; Gebo, 1992; Prang, 2015). Furthermore, a reduction in the length of the talar neck could lessen stress in the neck caused by weight transfer along the medial side during push-off (Harcourt-Smith, 2002). Clinical studies have suggested that flatfeet in humans are associated with a sagittally-longer talus relative to talar height and width, as well as with a more oval talar head (Anderson et al., 1997; Peeters et al., 2013). This configuration is paralleled in the arrangement of trochlear, navicular and posterior calcaneal facets in African apes (Fig. 12c), corroborating the idea that relative positions of the three major articular talar facets may reflect the development and presence of the medial longitudinal arch.

Because australopiths ( $A$. afarensis, $A$. africanus, $A$. sediba) are more similar to African apes in this regard, our results may indicate that the medial longitudinal arch could be entirely absent or incipient in australopiths (contra Stern and Susman, 1983; Lamy, 1986; Raichlen et al., 2010; Ward et al., 2011; Prang, 2015), implying that its fully developed form is a derived feature that only characterizes the genus Homo (Harcourt-Smith, 2002; Gebo and Schwartz, 2006; DeSilva and Throckmorton, 2010; Pontzer et al., 2010; Harcourt-Smith et al., 2015; Prang, 2015; Holowka and Lieberman, 2018). Indeed, to the best of our knowledge, the oldest direct (i.e., footprint) evidence of a clearly developed longitudinally arched foot comes from lleret, Kenya, dated to $1.5 \mathrm{Ma}$ and potentially attributed to $H$. erectus (Bennett et al., 2009; Hatala et al., 2016b). The development of a high medial longitudinal arch in Homo specimens represents an adaptation for storing elastic energy, which is helpful in long-distance walking and running (Bramble and Lieberman, 2004; 
Holowka and Lieberman, 2018). However, the evolution of the longitudinal arch is controversial since many authors have argued for the presence of some form of a longitudinal arch in $A$. afarensis based on foot bone characteristics (Stern and Susman, 1983; Lamy, 1986; Ward et al., 2011; Prang, 2015) and the 3.6 Ma Laetoli footprints (Tanzania) (Day and Wickens, 1980; Raichlen et al., 2010; Raichlen and Gordon, 2017), even though it may have been reduced in form when compared to the more fully developed arch expressed by H. sapiens (Bennett et al., 2009; Crompton et al., 2012; Prang, 2015; Hatala et al., 2016a; Prang, 2016c; Holowka and Lieberman, 2018). Despite disagreement in the degree of expression of the medial longitudinal arch of australopiths amongst all of these studies (i.e., absent or low), our results suggest that the stiffness achieved at the talonavicular joint in $A$. afarensis might have favored a human-like push-off even if it were coupled with an absent or incipient medial longitudinal arch. Thus, the increased relative stiffness of the medial mid-tarsal region may be a prior condition that enabled later development of the longitudinal arch (DeSilva, 2010; Ward et al., 2011) .

The fact that $A$. afarensis is more Homo-like in its talonavicular joint compared to $A$. africanus and A. sediba entails speculations on the phylogenetic relationship between $A$. afarensis and Homo (Kimbel and Delezene, 2009; Villmoareet al., 2015). Currently available craniodental evidence supports the hypothesis that $A$. africanus is more closely related to Homo (Strait and Grine, 2004; Irish et al., 2013), which if the case, leads us to hypothesize that the evolution of navicular facet morphology in $A$. afarensis and Homo could be an example of convergence. However, some postcranial findings (e.g., a more human-like upper/lower limb size proportion, extended hip and extended knee, orthogonally oriented tibia, human-like talar axis angle and robust calcaneal tuberosity) indicate that $A$. afarensis shares more similar postcranial characteristics with Homo than more recent specimens such as $A$. africanus and $A$. sediba (Latimer et al., 1987, 1989; Harcourt-Smith, 2002; Green et al., 2007; DeSilva, 2009; Zipfel et al., 2011; Haile-Selassie et al., 2012; DeSilva et al., 2013; Prang, 2015; Prang, 2016a; Boyle et al., 2018). Therefore, an alternative hypothesis for this similarity include a scenario in which $A$. afarensis is ancestral to Homo, but additional morphological phylogenetic analyses are required to shed light on such an unresolved question (Prang, 2015). 
One of the aims of this work was to assess if phenetic variation across the three tali attributed to $A$. africanus (StW 88, StW 363 and StW 486) could indicate the presence of different species at Sterkfontein (Clarke, 2013; Su and Carlson, 2017). Phenetic distances were calculated on the trochlea (Fig. 10) and on the combination of the trochlea and the medial malleolar facet (SOM Fig. S6). Results show that $A$. africanus exhibits larger intra-group distances than those obtained by resampling $H$. sapiens specimens, but not as large as the distances exhibited by Pan and Gorilla, suggesting that, based on external trochlear morphology and the combination of trochlear morphology and the medial malleolar facet, StW 363, StW 486 and StW 88 may be attributed to the same species or deme or to different ones depending on the comparative extant group used here.

The present study aims to increase our knowledge of the evolution of the hominin talus focusing on comparative morphological changes in order to better inform presumed biomechanical demands of bipedalism. However, a common limit when interpreting functional signals from variation in talar shape is the paucity of equivalent studies on living subjects. Furthermore, as cineradiographic or similar types of studies of extant hominids eventually will provide information about how articulating bones move in $3 \mathrm{D}$ relative to the talus (e.g., better characterize loading patterns), integrating results of the current study with those from similar studies of other tarsals would be beneficial to further interpreting the nature of the longitudinal arch and human-like toe-off. This could ultimately increase our capability to interpret functionally-related talar traits of extinct hominins.

\section{Conclusion}

Overall, this study provides an opportunity to extract a more comprehensive understanding of habitual bipedal locomotor adaptations in the hominin foot as they change over time from the perspective of the talus, and thus it sheds light on the evolutionary steps that have led to obligate bipedalism in modern humans. Lateral malleolar and navicular facets exhibit modern human-like form (i.e., structured for bipedal efficiency) earlier in the human evolutionary lineage than other facets of the talus. More specifically, during the earliest phases of the evolution of bipedalism, selective pressures appear to have produced a more stable talonavicular joint, thus promoting 
weight transfer along the medial column of the foot during push-off, and a less inverted posture of the foot in hominins. Among australopiths, A. afarensis appears to be more Homo-like, although a well-developed longitudinal arch probably did not emerge until the appearance of Homo. Indeed, the combination of the trochlea, and navicular and posterior calcaneal facets reflects a gradual acquisition of the longitudinal arch from australopiths to Homo marking the transition from facultative to obligate bipedalism.

\section{Acknowledgments}

This project has received funding from the European Research Council (ERC) under the European Union's Horizon 2020 research and innovation programme (grant agreement No 724046 SUCCESS; www.erc-success.eu). We are grateful to the Liang Bua Team" and "The National Research Centre for Archaeology, Indonesia" for access to the model of LB1-15. We thank Norman Macleod for access to the NHM's Konica Minolta scanner and the following curators and their institutions for access to material: Christophe Soligo, Department of Anthropology, UCL; Richard Kraft and Mike Schweissing, Zoologische Staatssammlung München; Malcolm Harman, Powell Cotton Museum, Kent; Paula Jenkins, Daphne Hills and Louise Tomsett, Department of Zoology, NHM, London; Illinois State Museum; Yohannes Haile-Selassie and Lyman Jellman, CMNH; Bernhard Zipfel, University of the Witwatersrand; Linda K. Gordon and Darrin P. Lunde, NMNH; Natasha Johnson, Mike Black and Paolo Pellegatti of the P.A. Hearst Museum, UC Berkeley, for access to Native American collection; Museo delle Mummie di Roccapelago. We thank Luisa Mingozzi and Denis Nicolini of the Unit of Radiology (S. Maria delle Croci Hospital of Ravenna) for assistance during the scanning of Italian collections. We thank the Dmanisi research team for support and access during data collection at Dmanisi Museum-Reserve Georgian National Museum. We thank Drs. David Miminoshvili and Giorgi Tsivtsivadze, the Department of Computed Tomography, Research Institute of Clinical Medicine (Todua Clinic) for allowing us to scan the Dmanisi talus in their facility. Access to the Krapina sample was made possible by the NESPOS (Neanderthal Studies Professional Online Service) Database 
(https://www.nespos.org/display/openspace/Home). We thank P. Mennecier and A. Froment (Museum National d'Histoire Naturelle, Departement Hommes, Natures, Societes) for providing digital models of La Ferrassie 1 and 2. 


\section{References}

Adams, D.C., Felice, R.N., 2014. Assessing trait covariation and morphological integration on phylogenies using evolutionary covariance matrices. PLoS One 9, e94335.

Adams, D.C., Otárola-Castillo, E., 2013. Geomorph: an R package for the collection and analysis of geometric morphometric shape data. Methods in Ecology and Evolution 4, 393-399.

Aiello, L., Dean, C., 1990. An Introduction to Human Evolutionary Anatomy. Academic Press, London.

Almécija, S., Tallman, M., Alba, D. M., Pina, M., Moyà-Solà, S., \& Jungers, W. L., 2013. The femur of Orrorin tugenensis exhibits morphometric affinities with both Miocene apes and later hominins. Nature Communications 4, 2888.

Anderson, J.G., Harrington, R., Ching, R.P., Tencer, A., Sangeorzan, B.J., 1997. Alterations in talar morphology associated with adult flatfoot. Foot \& Ankle International 18, 705-709.

Antón, S.C., Potts, R., Aiello, L., 2014. Evolution of early Homo: an integrated biological perspective. Science 345, 1236828.

Arnold, C., Matthews, L.J., Nunn, C.L., 2010. The 10kTrees Website: A new online resource for primate phylogeny. Evolutionary Anthropology: Issues, News, and Reviews 19, 114-118.

Bailey, S.E., Benazzi, S., Hublin, J.J., 2014. Allometry, merism, and tooth shape of the upper deciduous M2 and permanent M1. American Journal of Physical Anthropology 154, 104-114.

Barnett, C.H., Napier, J.R., 1952. The axis of rotation at the ankle joint in man. Its influence upon the form of the talus and the mobility of the fibula. Journal of Anatomy $86,1-9$.

Belcastro, M.G., Bonfiglioli, B., Pedrosi, M.E., Zuppello, M., Tanganelli, V., Mariotti, V., 2017. The history and composition of the identified human skeletal collection of the Certosa cemetery (Bologna, Italy, 19th-20th century). International Journal of Osteoarchaeology 27, 912-925.

Benazzi, S., Bookstein, F.L., Strait, D.S., Weber, G.W., 2011. A new OH5 reconstruction with an assessment of its uncertainty. Journal of Human Evolution 61, 75-88. 
Bennett, M.R., Harris, J.W.K., Richmond, B.G., Braun, D.R., Mbua, E., Kiura, P., Olago, D., Kibunjia, M., Omuombo, C., Behrensmeyer, A.K., Huddart, D., Gonzalez, S., 2009. Early hominin foot morphology based on 1.5-million-year-old footprints from lleret, Kenya. Science 323, 1197-1201.

Boyle, E.K., McNutt, E.J., Sasaki, T., Suwa, G., Zipfel, B., DeSilva, J.M., 2018. A quantification of calcaneal lateral plantar process position with implications for bipedal locomotion in Australopithecus. Journal of Human Evolution 123, 24-34.

Bramble, D.M., Lieberman, D.E., 2004. Endurance running and the evolution of Homo. Nature 432, 345-352.

Carlson, K.J., 2005. Investigating the form-function interface in African apes: relationships between principal moments of area and positional behaviors in femoral and humeral diaphyses. American Journal of Physical Anthropology 127, 312-334.

Clarke, R.J., 2013. Australopithecus from Sterkfontein caves, South Africa. In: Reed, K., Fleagle, J., Leakey, R. (Eds.), The Paleobiology of Australopithecus. Springer, Dordrecht, pp. 105123.

Crompton, R.H., 2016. The hominins: a very conservative tribe? Last common ancestors, plasticity and ecomorphology in Hominidae. Or, what's in a name? Journal of Anatomy 228, 686-699.

Crompton, R.H., Pataky, T.C., Savage, R., D’Aout, K., Bennett, M.R., Day, M.H., Bates, K., Morse, S., Sellers, W.I., 2012. Human-like external function of the foot, and fully upright gait, confirmed in the 3.66 million year old Laetoli hominin footprints by topographic statistics, experimental footprint-formation and computer simulation. Journal of The Royal Society Interface 9, 707-719.

Day, M. H., Wood, B.A., 1968. Functional affinities of the Olduvai Hominid 8 talus. Man 3, 440455. 
Day, MH, Wickens, E., 1980. Laetoli Pliocene hominid footprints and bipedalism. Nature 286, 385387.

DeSilva, J., McNutt, E., Benoit, J., Zipfel, B., 2019. One small step: a review of Plio-Pleistocene hominin foot evolution. American Journal of Physical Anthropology. 168, 63-140.

DeSilva, J.M., 2009. Functional morphology of the ankle and the likelihood of climbing in early hominins. Proceedings of the National Academy of Sciences 106, 6567e6572.

DeSilva, J.M., 2010. Revisiting the 'midtarsal break'. American Journal of Physical Anthropology $141,245-258$.

DeSilva, J.M., Gill, C.M., Prang, T.C., Bredella, M.A., Alemseged, Z., 2018a. A nearly complete foot from Dikika, Ethiopia and its implications for the ontogeny and function of Australopithecus afarensis. Science Advances 4, 1-9.

DeSilva, J.M., Carlson, K.J., Claxton, A.G., Harcourt-Smith, W.E.H., McNutt, E.J., Sylvester, A.D., Walker, C.S., Zipfel, B., Churchill, S.E., and Berger, L.R. 2018b. Special issue: Australopithecus sediba -The anatomy of the lower limb skeleton of Australopithecus sediba. PaleoAnthropology 2018, 357-405

DeSilva, J.M., Holt, K.G., Churchill, S.E., Carlson, K.J., Walker, C.S., Zipfel, B., Berger, L.R., 2013. The lower limb and mechanics of walking in Australopithecus sediba. Science 340, 1232999.

DeSilva, J.M., Throckmorton, Z.J., 2010. Lucy's flat feet: the relationship between the ankle and rearfoot arching in early hominins. PloS One 5, e14432.

Doran, D.M., 1993. Comparative locomotor behavior of chimpanzees and bonobos: the influence of morphology on locomotion. American Journal of Physical Anthropology 91, 83-98.

Doran, D.M., 1996. Comparative positional behavior of the African apes. In: McGrew, W. C., Marchant, L. F., Nishida, T. E. (Eds.), Great Ape Societies. Cambridge University Press.

Doran, D.M., McNeilage, A., 1998. Gorilla ecology and behavior. Evolutionary Anthropology 6, $120-131$. 
Dowdeswell, M.R., Jashashvili, T., Patel, B.A., Lebrun, R., Susman, R.L., Lordkipanidze, D., Carlson, K.J., 2017. Adaptation to bipedal gait and fifth metatarsal structural properties in Australopithecus, Paranthropus, and Homo. Comptes Rendus - Palevol. 16, 585-599.

Drapeau, M.S.M., Harmon, E.H., 2013. Metatarsal torsion in monkeys, apes, humans and australopiths. Journal of Human Evolution 64, 93-108.

Dunn, R.H., Tocheri, M.W., Orr, C.M., Jungers, W.L., 2014. Ecological divergence and talar morphology in gorillas. American Journal of Physical Anthropology 153, 526-41.

Elftman, H., Manter, J., 1935. Chimpanzee and human feet in bipedal walking. American Journal of Physical Anthropology 20, 69-79.

Farris, D.J., Kelly, L.A., Cresswell, A.G., Lichtwark, G.A., 2019. The functional importance of human foot muscles for bipedal locomotion. Proceedings of the National Academy of Sciences 116, 1645-1650.

Fernández, P.J., Holowka, N.B., Demes, B., Jungers, W.L., 2016. Form and function of the human and chimpanzee forefoot: implications for early hominin bipedalism. Scientific Reports 6, 110.

Fernández, P.J., Mongle, C.S., Leakey, L., Proctor, D.J., Orr, C.M., Patel, B.A., Almécija, S., Tocheri, M.W., Jungers, W.L., 2018. Evolution and function of the hominin forefoot. Proceedings of the National Academy of Sciences 115, 8746-8751

Finestone, E.M., Brown, M.H., Ross, S.R., Pontzer, H., 2018. Great ape walking kinematics: implications for hominoid evolution. American Journal of Physical Anthropology 166, 43-55.

Fleagle, J. G. 2013. Primate Adaptation and Evolution. Academic Press.

Frelat, M.A., Shaw, C.N., Sukhdeo, S., Hublin, J.J., Benazzi, S., Ryan, T.M., 2017. Evolution of the hominin knee and ankle. Journal of Human Evolution 108, 147-160.

Gebo, D.L., 1992. Plantigrady and foot adaptation in African apes: implications for hominid origins. American Journal of Physical Anthropology 89, 29-58. 
Gebo, D.L., Schwartz, G.T., 2006. Foot bones from Omo: implications for hominid evolution. American Journal of Physical Anthropology 129, 499-511.

Gill, C.M., Bredella, M.A., DeSilva, J.M., 2015. Skeletal development of hallucal tarsometatarsal joint curvature and angulation in extant apes and modern humans. Journal of Human Evolution 88, 137-145.

Green, D.J., Gordon, A.D., Richmond, B.G., 2007. Limb-size proportions in Australopithecus afarensis and Australopithecus africanus. Journal of Human Evolution 52, 187-200.

Greiner, T.M., Ball, K.A., 2014. Kinematics of primate midfoot flexibility. American Journal of Physical Anthropology. 155, 610-620.

Griffin, N.L., D’Aočt, K., Richmond, B., Gordon, A., Aerts, P., 2010. Comparative in vivo forefoot kinematics of Homo sapiens and Pan paniscus. Journal of Human Evolution 59, 608-619.

Griffin, N.L., Miller, C.E., Schmitt, D., Ao, K.D., 2015. Understanding the evolution of the windlass mechanism of the human foot from comparative anatomy: insights, obstacles, and future directions. American Journal of Physical Anthropology 156, 1-10.

Gunz, P., Mitteroecker, P., 2013. Semilandmarks: a method for quantifying curves and surfaces. Hystrix 24, 103-109.

Haeusler, M., McHenry, H.M., 2004. Body proportions of Homo habilis reviewed. Journal of Human Evolution 46, 433-465.

Haile-Selassie, Y., 2001. Late Miocene hominids from the Midle Awash, Ethiopia. Nature 412, 178.

Haile-Selassie, Y., Saylor, B.Z., Deino, A., Levin, N.E., Alene, M., Latimer, B.M., 2012. A new hominin foot from Ethiopia shows multiple Pliocene bipedal adaptations. Nature. 483, 565569.

Harcourt-Smith, W.E.H., 2002. Form and function in the hominoid tarsal skeleton. Ph.D. Dissertation, University of London. 
Harcourt-Smith, W.E.H., 2016. Early hominin diversity and the emergence of the genus Homo. Journal of Anthropological Sciences 94, 19-27.

Harcourt-Smith, W.E.H., Aiello, L., 2004. Fossils, feet and the evolution of human bipedal locomotion. Journal of Anatomy 204, 403-416.

Harcourt-Smith, W.H.E., 2010. The first hominins and the origins of bipedalism. Evolution: Education and Outreach 3, 333-340.

Harcourt-Smith, W.H.E., Throckmorton, Z., Congdon, K.A., Zipfel, B., Deane, A.S., Drapeau, M.S.M., Churchill, S.E., Berger, L.R., DeSilva, J.M., 2015. The foot of Homo naledi. Nature Communications 6, 1-8.

Hatala, K.G., Demes, B., Richmond, B.G., 2016a. Laetoli footprints reveal bipedal gait biomechanics different from those of modern humans and chimpanzees. Proceedings of the Royal Society B: Biological Sciences 283, 20160235.

Hatala, K.G., Roach, N.T., Ostrofsky, K.R., Wunderlich, R.E., Dingwall, H.L., Villmoare, B.A., Green, D.J., Harris, J.W.K., Braun, D.R., Richmond, B.G., 2016b. Footprints reveal direct evidence of group behavior and locomotion in Homo erectus. Scientific Reports 6, 1-9.

Holowka, N.B., Lieberman, D.E., 2018. Rethinking the evolution of the human foot: insights from experimental research. The Journal of Experimental Biology 221, jeb174425.

Holowka, N.B., O’Neill, M.C., Thompson, N.E., Demes, B., 2017a. Chimpanzee and human midfoot motion during bipedal walking and the evolution of the longitudinal arch of the foot. Journal of Human Evolution 104, 23-31.

Holowka, N. B., O'Neill, M. C., Thompson, N. E., \& Demes, B., 2017b. Chimpanzee ankle and foot joint kinematics: arboreal versus terrestrial locomotion. American Journal of Physical Anthropology 164, 131-147.

Huson, A., 1991. Functional anatomy of the foot. Disorders of the Foot and Ankle 1, 409-431.

Irish, J. D., Guatelli-Steinberg, D., Legge, S. S., de Ruiter, D. J., Berger, L.R., 2013. Dental 
morphology and the phylogenetic "place" of Australopithecus sediba. Science 340, 1233062.

Jashashvili, T., Dowdeswell, M.R., Lebrun, R., Carlson, K.J., 2015. Cortical structure of hallucal metatarsals and locomotor adaptations in hominoids. PLoS One 10, e0117905.

Jungers, W.L., Harcourt-Smith, W.E.H., Wunderlich, R.E., Tocheri, M.W., Larson, S.G., Sutikna, T., Due, R.A., Morwood, M.J., 2009. The foot of Homo floresiensis. Nature 459, 81-84.

Kidd, R. 2004. On the nature of morphology: selected canonical variates analyses of the hominoid hindtarsus and their interpretation. In Anapol, F., German, R. Z., Jablonski, N. G., (Eds.), Shaping Primate Evolution. Cambridge University Press, p. 162-192.

Kidd, R., 1999. Evolution of the rearfoot. A model of adaptation with evidence from the fossil record. Journal of the American Podiatric Medical Association 89, 2-17.

Kidd, R. S., O'Higgins, P., Oxnard, C. E., 1996. The OH8 foot: a reappraisal of the functional morphology of the hindfoot utilizing a multivariate analysis. Journal of Human Evolution 31, 269-291.

Kimbel, W.H., Delezene, L.K., 2009. "Lucy" redux: A review of research on Australopithecus afarensis. American Journal of Physical Anthropology 140, 2-48.

Kivell, T.L., Schmitt, D., 2009. Independent evolution of knuckle-walking in African apes shows that humans did not evolve from a knuckle-walking ancestor. Proceedings of the National Academy of Sciences 106, 14241-14246.

Klingenberg, C.P., 2016. Size, shape, and form: concepts of allometry in geometric morphometrics. Development Genes and Evolution 226, 113-137.

Knigge, R.P., Tocheri, M.W., Orr, C.M., 2015. Three-dimensional geometric morphometric analysis of talar morphology in extant gorilla taxa from highland and lowland habitats. The Anatomical Record 298, 277-290.

Lamy, P., 1986. The settlement of the longitudinal plantar arch of some african Plio-Pleistocene hominids: a morphological study. Journal of Human Evolution 15, 31-46. 
Latimer, B., Ohman, J. C., \& Lovejoy, C. O. 1987. Talocrural joint in African hominoids: implications for Australopithecus afarensis. American Journal of Physical Anthropology 74, 155-175.

Latimer, B., Lovejoy, C.O., 1990. Hallucal tarsometatarsal joint. American Journal of Physical Anthropology. 82, 125-133.

Latimer, B., Lovejoy, C.O., 1989. The calcaneus of Australopithecus afarensis and its implications for the evolution of bipedality. American Journal of Physical Anthropology 78, 369-386.

Latimer, B., Ohman, J.C., Lovejoy, C.O., 1987. Talocrural joint in African hominoids: implications for Australopithecus afarensis. American Journal of Physical Anthropology 74, 155-175.

Lordkipanidze, D., León, M.S.P. De, Margvelashvili, A., Rak, Y., Rightmire, G.P., Vekua, A., Zollikofer, C.P.E., 2013. A complete skull from Dmanisi, Georgia, and the evolutionary biology of early Homo. Science 342, 326-331.

Lovejoy, C.O., Latimer, B., Suwa, G., Asfaw, B., White, T.D., 2009. Combining prehension and propulsion: the foot of Ardipithecus ramidus. Science 326, 72-72e8.

Marchi, D., 2007. Relative strength of the tibia and fibula and locomotor behavior in hominoids. Journal of Human Evolution 53, 647-655.

Marchi, D., 2015. Using the morphology of the hominoid distal fibula to interpret arboreality in Australopithecus afarensis. Journal of Human Evolution 85, 136-148.

McNutt, E.J., Zipfel, B., DeSilva, J.M., 2018. The evolution of the human foot. Evolutionary Anthropology 27, 197-217.

Mitteroecker, P., Gunz, P., Windhager, S., Schaefer, K., 2013. A brief review of shape, form, and allometry in geometric morphometrics, with applications to human facial morphology. Hystrix. $24,1-8$

Nowak, M.G., Carlson, K.J., Patel, B.A., 2010. Apparent density of the primate calcaneo-cuboid joint and its association with locomotor mode, foot posture, and the "midtarsal break". American Journal of Physical Anthropology 142, 180-193. 
O’Neill, M.C., Lee, L.F., Demes, B., Thompson, N.E., Larson, S.G., Stern, J.T., Umberger, B.R., 2015. Three-dimensional kinematics of the pelvis and hind limbs in chimpanzee ( Pan troglodytes) and human bipedal walking. Journal of Human Evolution 86, 32-42.

Parr, W.C.H., Chatterjee, H.J., Soligo, C., 2011a. Inter- and intra-specific scaling of articular surface areas in the hominoid talus. Journal of Anatomy 218, 386-401.

Parr, W.C.H., Ruto, A., Soligo, C., Chatterjee, H.J., 2011b. Allometric shape vector projection: A new method for the identification of allometric shape characters and trajectories applied to the human astragalus (talus). Journal of Theoretical Biology 272, 64-71.

Parr, W.C.H., Soligo, C., Smaers, J., Chatterjee, H.J., Ruto, A., Cornish, L., Wroe, S., 2014. Threedimensional shape variation of talar surface morphology in hominoid primates. Journal of Anatomy 225, 42-59.

Peeters, K., Schreuer, J., Burg, F., Behets, C., Van Bouwel, S., Dereymaeker, G., Sloten, J. Vander, Jonkers, I., 2013. Alterated talar and navicular bone morphology is associated with pes planus deformity: a CT-scan study. Journal of Orthopaedic Research 31, 282-287.

Pontzer, H., 2012. Ecological energetics in early Homo. Current Anthropology 53, S346-S358.

Pontzer, H., Rolian, C., Rightmire, G.P., Jashashvili, T., Ponce de León, M.S., Lordkipanidze, D., Zollikofer, C.P.E., 2010. Locomotor anatomy and biomechanics of the Dmanisi hominins. Journal of Human Evolution 58, 492-504.

Prang, T.C., 2015. Rearfoot posture of Australopithecus sediba and the evolution of the hominin longitudinal arch. Scientific reports 5, 17677.

Prang, T.C., 2016a. The subtalar joint complex of Australopithecus sediba. Journal of Human Evolution 90, 105-119.

Prang, T.C., 2016b. Conarticular congruence of the hominoid subtalar joint complex with implications for joint function in Plio-Pleistocene hominins. American Journal of Physical Anthropology 160, 446-457. 
Prang, Thomas C., 2016c. Reevaluating the functional implications of Australopithecus afarensis navicular morphology. Journal of Human Evolution 97, 73-85.

Preuschoft, H., 2004. Mechanisms for the acquisition of habitual bipedality: are there biomechanical reasons for the acquisition of upright bipedal posture? Journal of Anatomy 204, 363-384.

Raichlen, D.A., Gordon, A.D., 2017. Interpretation of footprints from Site S confirms human-like bipedal biomechanics in Laetoli hominins. Journal of Human Evolution 107, 134-138.

Raichlen, D.A., Gordon, A.D., Harcourt-smith, W.E.H., Foster, A.D., Randall, W., 2010. Laetoli footprints preserve earliest direct evidence of human-like bipedal biomechanics. PLoS One 5, e9769.

R Core Team, 2017. R: A language and environment for statistical computing. Vienna, Austria: R Foundation for Statistical Computing.

Remis, M., 1995. Effects of body size and social context on the arboreal activities of lowland gorilla Central African Republic. American Journal of Physical Anthropology 97, 413-433.

Remis, M.J., 1999. Tree structure and sex differences in arboreality among western lowland gorillas Gorilla gorilla gorilla. Primates 40, 383-396.

Rhoads, J.G., Trinkaus, E., 1977. Morphometrics of the Neandertal talus. American Journal of Physical Anthropology 46, 29-43.

Richmond, B. G., Begun, D. R. \& Strait, D. S., 2001. Origin of human bipedalism: the knucklewalking hypothesis revisited. Yearbook of Physical Anthropology 44, 70-105.

Richmond, B.G., Jungers, W.L., 2008. Orrorin tugenensis femoral morphology and the evolution of hominin bipedalism. Science 319, 1662-1665

Rosas, A., Ferrando, A., Bastir, M., García-Tabernero, A., Estalrrich, A., Huguet, R., GarcíaMartínez, D., Pastor, J.F., de la Rasilla, M., 2017. Neandertal talus bones from El Sidrón site (Asturias, Spain): a 3D geometric morphometrics analysis. American Journal of Physical 
Anthropology. 164, 394-415.

Ruff, C., 2008. Femoral/humeral strength in early african Homo erectus. Journal of Human Evolution 54, 383-390.

Ryan, T.M., Carlson, K.J., Gordon, A.D., Jablonski, N., Shaw, C.N., Stock, J.T., 2018. Human-like hip joint loading in Australopithecus africanus and Paranthropus robustus. Journal of Human Evolution 121, 12-24.

Sarrafian, S.K., 1987. Functional characteristics of the foot and plantar aponeurosis under tibiotalar loading. Foot \& ankle 8, 4-18.

Schlager, S., 2017. Morpho and Rvcg - Shape Analysis in R: R-Packages for geometric morphometrics, shape analysis and surface manipulations. In: Zheng, G., Li, S., Székely, G., (Eds.), Statistical shape and deformation analysis: methods, implementation and applications. Academic Press, p. 217-256.

Shaw, C.N., Ryan, T.M., 2012. Does skeletal anatomy reflect adaptation to locomotor patterns? Cortical and trabecular architecture in human and nonhuman anthropoids. American Journal of Physical Anthropology 147, 187-200.

Slice, D.E., 2006. Modern Morphometrics in Physical Anthropology. Springer Science \& Business Media, New York.

Sorrentino, R., Stephens, N.B., Carlson, K.J., Figus, C., Fiorenza, L., Frost, S., Harcourt-Smith, W., Parr, W., Saers, J., Turley, K., Wroe, S., Belcastro, M.G., Ryan, T.M., Benazzi, S., 2019. The influence of mobility strategy on the modern human talus. American Journal of Physical Anthropology. DOI: 10.1002/ajpa.23976.

Steele, D.G., Bramblett, C.A., 1988. The Anatomy and Biology of the Human Skeleton. Texas A\&M University Press.

Stern, J.T., Susman, R.L., 1983. The locomotor anatomy of Australopithecus afarensis. American Journal of Physical Anthropology 60, 279-317. 
Strait, D.S., Grine, F.E., 2004. Inferring hominoid and early hominid phylogeny using craniodental characters: the role of fossil taxa. Journal of Human Evolution 47, 399-452.

Su, A., Carlson, K.J., 2017. Comparative analysis of trabecular bone structure and orientation in South African hominin tali. Journal of Human Evolution 106, 1-18.

Su, A., Wallace, I.J., Nakatsukasa, M., 2013. Trabecular bone anisotropy and orientation in an Early Pleistocene hominin talus from East Turkana, Kenya. Journal of Human Evolution 64, 667-677.

Turley, K., Frost, S.R., 2013. The shape and presentation of the catarrhine talus: a geometric morphometric analysis. Anatomical Record 296, 877-890.

Turley, K., Frost, S.R., 2014. The appositional articular morphology of the talo-crural joint: the influence of substrate use on joint shape. Anatomical Record 297, 618-629.

Venkataraman, V. V., Kraft, T.S., DeSilva, J.M., Dominy, N.J., 2013a. Phenotypic plasticity of climbing-related traits in the ankle joint of great apes and rainforest hunter-gatherers. Human Biology 85, 309-328.

Venkataraman, V. V, Kraft, T.S., Dominy, N.J., 2013b. Tree climbing and human evolution. Proceedings of the National Academy of Sciences 110, 1237-1242.

Villmoare, B., Kimbel, W.H., Chalachew, S., Campisano, C.J., DiMaggio, E.N., Rowan, J., Braun, R., Arrowsmith, J.R., Reed, K.E., 2015. Early Homo at 2.8 Ma from Ledi-Geraru, Afar, Ethiopia. Science 347, 1352-1355.

Ward, C.V., Kimbel, W.H., Johanson, D.C., 2011. Complete fourth metatarsal and arches in the foot of Australopithecus afarensis. Science 331, 750-753.

Ward, C. V., 2002. Interpreting the posture and locomotion of Australopithecus afarensis: where do we stand? American Journal of Physical Anthropology 119, 185-215. 
White, T.D., Asfaw, B., Beyene, Y., Haile-Selassie, Y., Lovejoy, O., Suwa, G., Woldegabriel, G., Lovejoy, C.O., Suwa, G., Woldegabriel, G., 2009. Ardipithecus ramidus and the paleobiology of early hominids. Science $326,64-86$.

Wolpoff, M.H., Senut, B., Pickford, M., Hawks, J., 2002. Palaeoanthropology: Sahelanthropus or 'Sahelpithecus'? Nature 419, 581-582.

Wunderlich, R.E., Ischinger, S.B., 2017. Foot use during vertical climbing in chimpanzees (Pan troglodytes). Journal of Human Evolution 109, 1-10.

Zipfel, B., DeSilva, J.M., Kidd, R.S., Carlson, K.J., Churchill, S.E., Berger, L.R., 2011. The foot and ankle of Australopithecus sediba. Science 333, 1417-1420.

Zollikofer, C.P.E., Ponce De León, M.S., Lieberman, D.E., Guy, F., Pilbeam, D., Likius, A., Mackaye, H.T., Vignaud, P., Brunet, M., 2005. Virtual cranial reconstruction of Sahelanthropus tchadensis. Nature 434, 755-759. 
Table 1. Landmarks of talar configuration.

\begin{tabular}{|c|c|}
\hline Landmarks & Labels $^{a}$ \\
\hline Most distal lateral point of contact & \\
\hline $\begin{array}{l}\text { between the medial malleolar facet and } \\
\text { the trochlear surface }\end{array}$ & 1 \\
\hline $\begin{array}{l}\text { Most proximal point of contact } \\
\text { between the medial malleolar facet and } \\
\text { the trochlear surface }\end{array}$ & 2 \\
\hline $\begin{array}{l}\text { Most proximal point of contact } \\
\text { between the lateral malleolar facet and } \\
\text { the trochlear surface }\end{array}$ & 3 \\
\hline $\begin{array}{l}\text { Most distal point of contact between } \\
\text { the lateral malleolar facet and the } \\
\text { trochlear surface }\end{array}$ & 4 \\
\hline $\begin{array}{l}\text { Most medial point of contact between } \\
\text { the head/navicular facet }\end{array}$ & 5 \\
\hline $\begin{array}{l}\text { Most lateral point on the } \\
\text { head/navicular facet }\end{array}$ & 6 \\
\hline $\begin{array}{l}\text { Most lateral point on the proximal } \\
\text { calcaneal facet }\end{array}$ & 7 \\
\hline $\begin{array}{l}\text { Deepest (most dorsal) point on the } \\
\text { proximal calcaneal facet }\end{array}$ & 8 \\
\hline $\begin{array}{l}\text { Most proximo-medial point on the } \\
\text { proximal calcaneal facet }\end{array}$ & 9 \\
\hline $\begin{array}{l}\text { Most disto-lateral point on the } \\
\text { proximal calcaneal facet }\end{array}$ & 10 \\
\hline $\begin{array}{l}\text { Most plantar point on the lateral } \\
\text { malleolar facet }\end{array}$ & 11 \\
\hline $\begin{array}{l}\text { Flexor hallucis longus: most distal } \\
\text { point on the medial margin }\end{array}$ & 12 \\
\hline $\begin{array}{l}\text { Flexor hallucis longus: most distal } \\
\text { point on the lateral margin }\end{array}$ & 13 \\
\hline $\begin{array}{l}\text { Flexor hallucis longus: intersection } \\
\text { with calcaneus curve }\end{array}$ & 14 \\
\hline $\begin{array}{l}\text { Flexor hallucis longus: most postero- } \\
\text { inferior prominent point }\end{array}$ & 15 \\
\hline
\end{tabular}




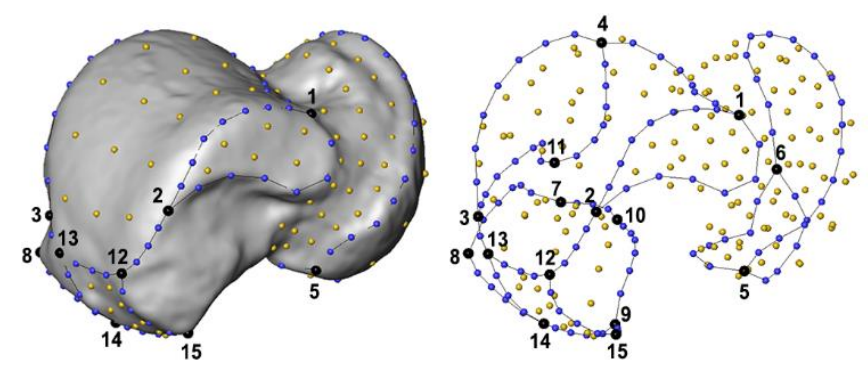

Figure 1. Talar configuration of landmarks and semi-landmarks: 15 fixed landmarks (black), 105 curve semi-landmarks (blue) and 131 surface semi-landmarks (orange). 


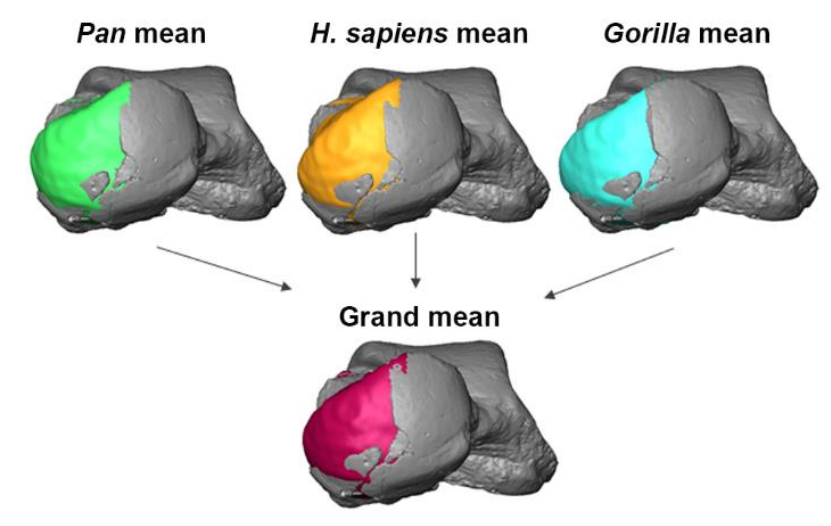

Figure 2. Digital reconstruction of specimen StW 88 based on TPS interpolation function. The color areas indicate the reconstructed portion of the talus based on the mean of Pan, Gorilla, $H$. sapiens and the pooled extant sample (grand mean) respectively. 
a

b

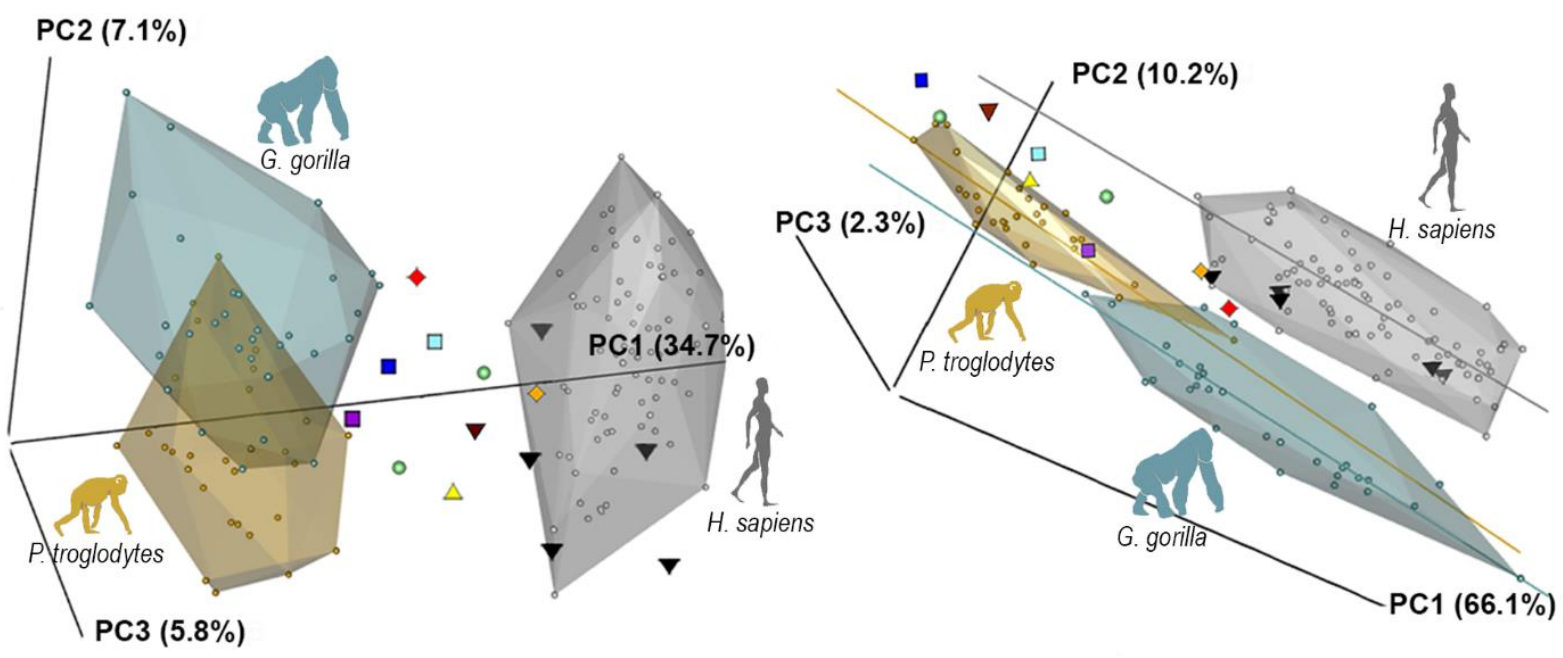

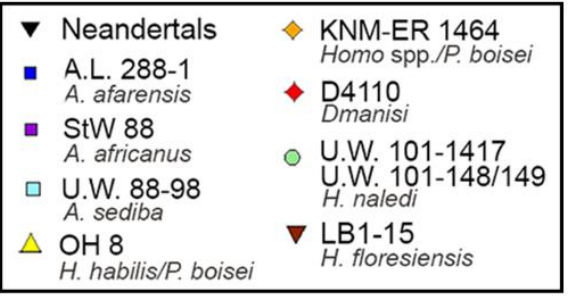
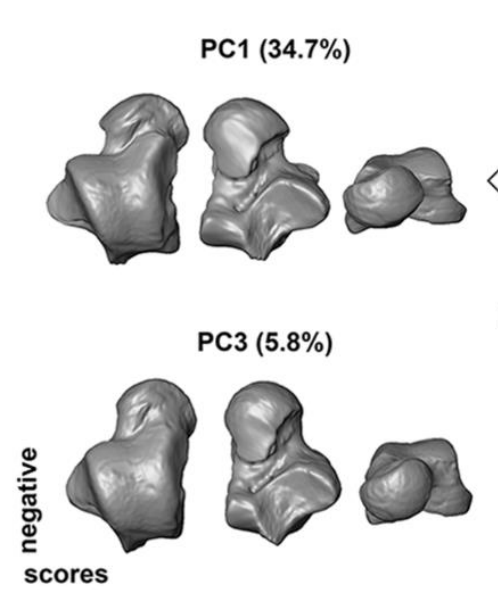
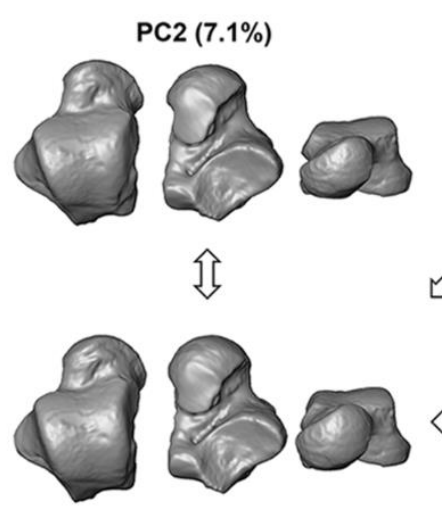

企

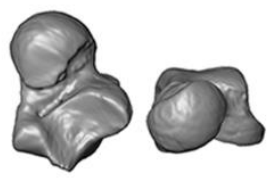

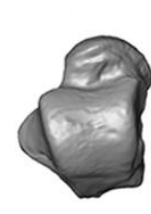

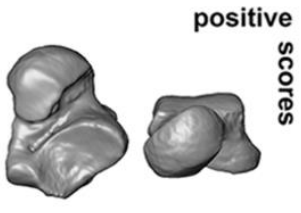

가
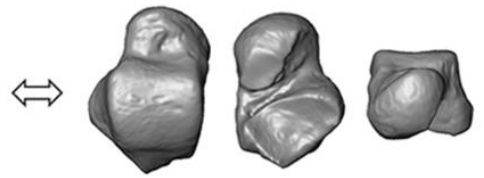

c

Figure 3. Whole talus. Shape space 3D PCA plot (a) and form space 3D PCA plot (b). Shape changes along the first three shape PCs (c) in dorsal, plantar and frontal views (from left to right). At the center of each cluster is mean shape.

49 


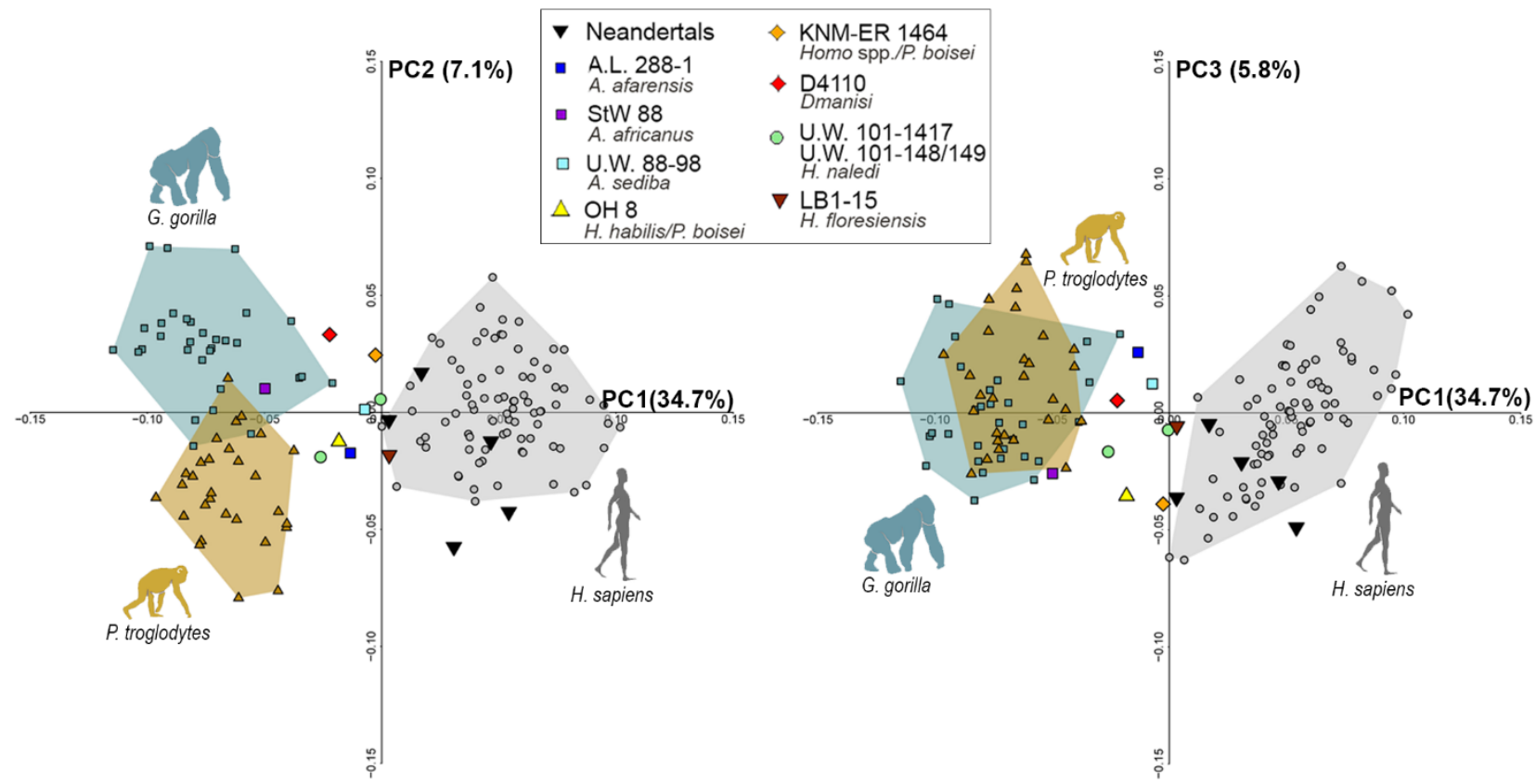

Figure 4. PCA of the whole talus in shape space depicting PC1 vs. PC2 (left) and PC1 vs. PC3 (right). 


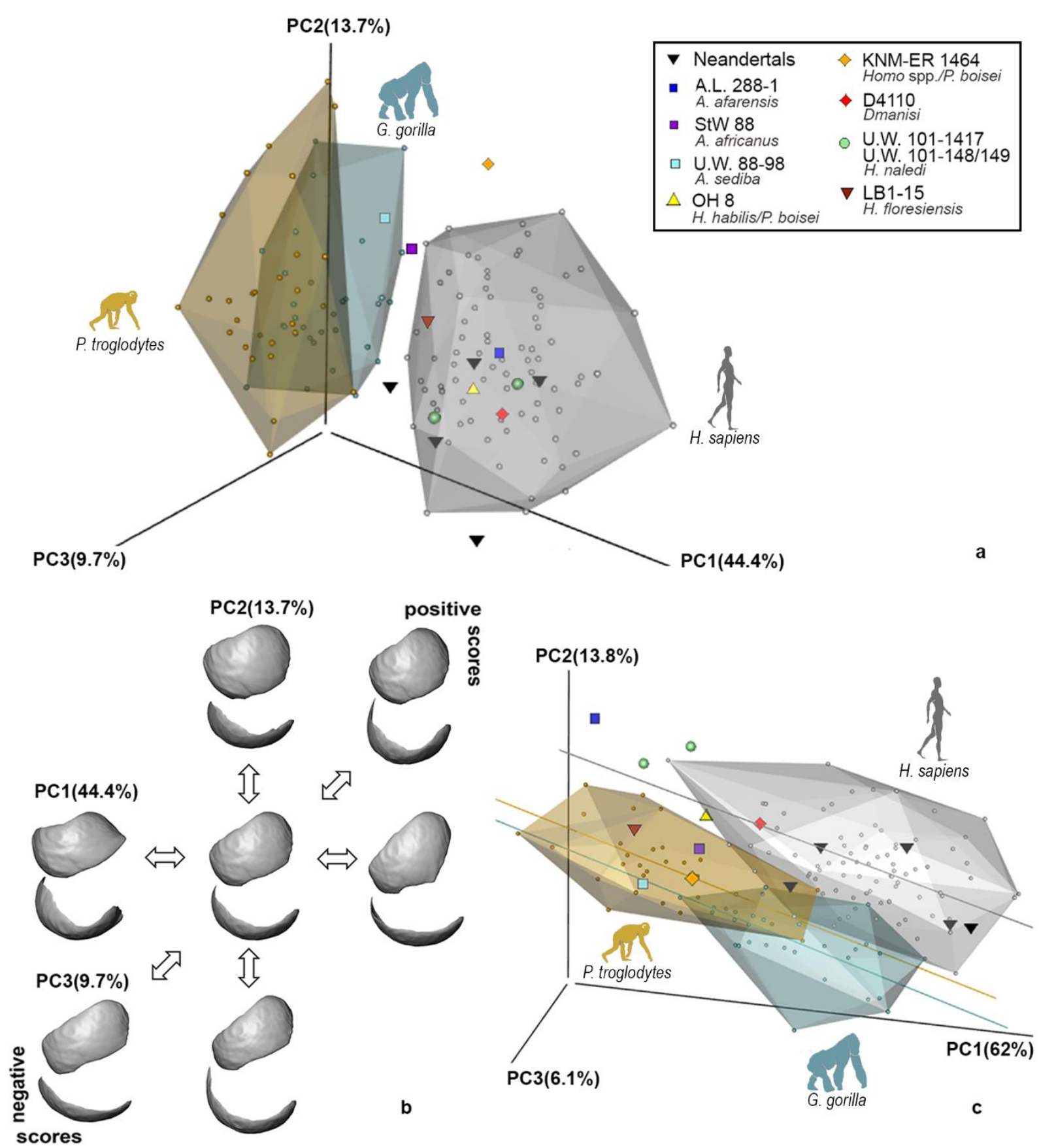

Figure 5. Navicular facet. Shape space 3D PCA plot (a) and form space 3D PCA plot (c). Shape changes along the first three shape PCs (b) in frontal (above) and dorsal (down) views. 


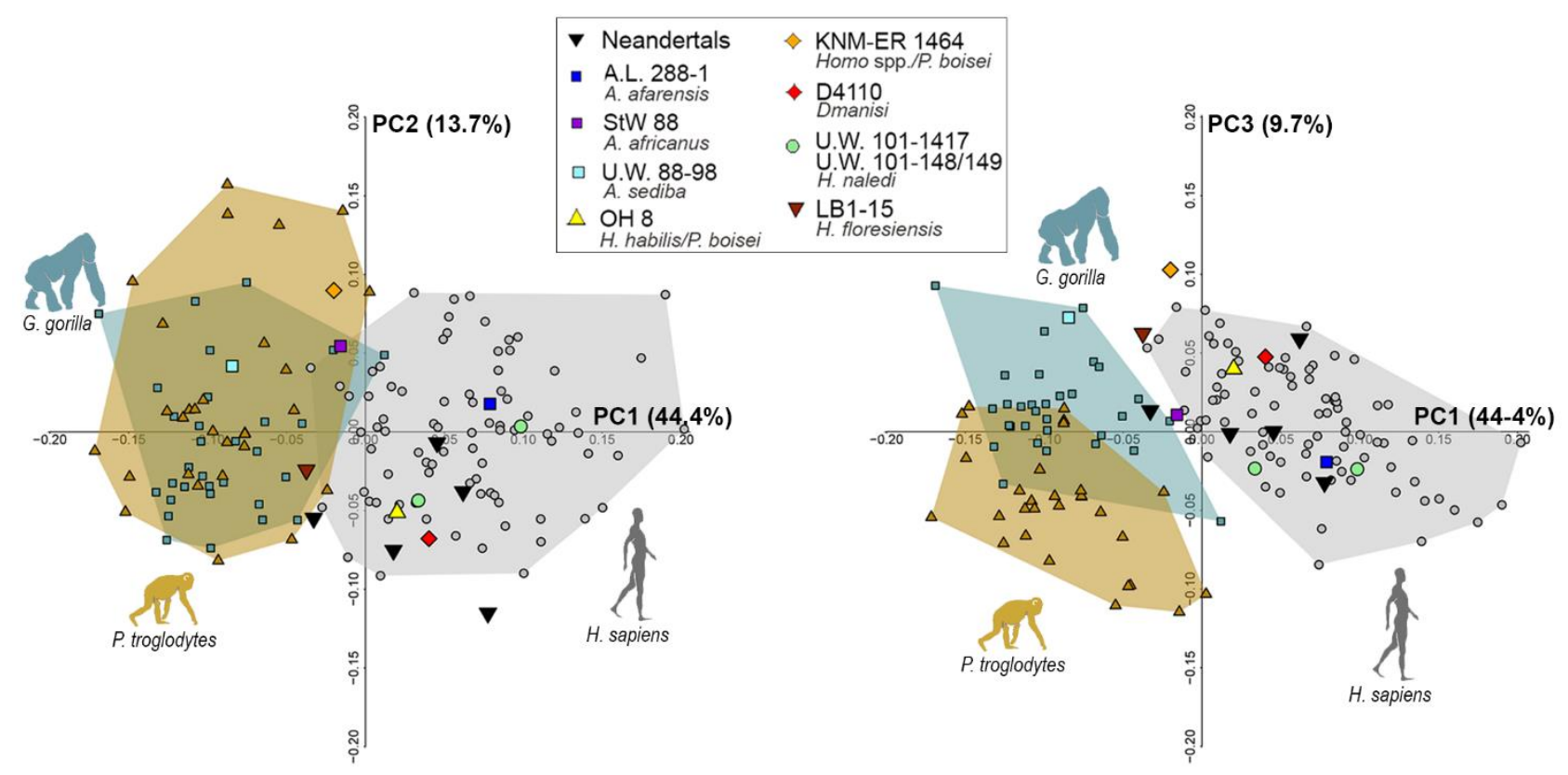

Figure 6. PCA of the navicular facet in shape space depicting PC1 vs. PC2 (left) and PC1 vs. PC3 (right). 

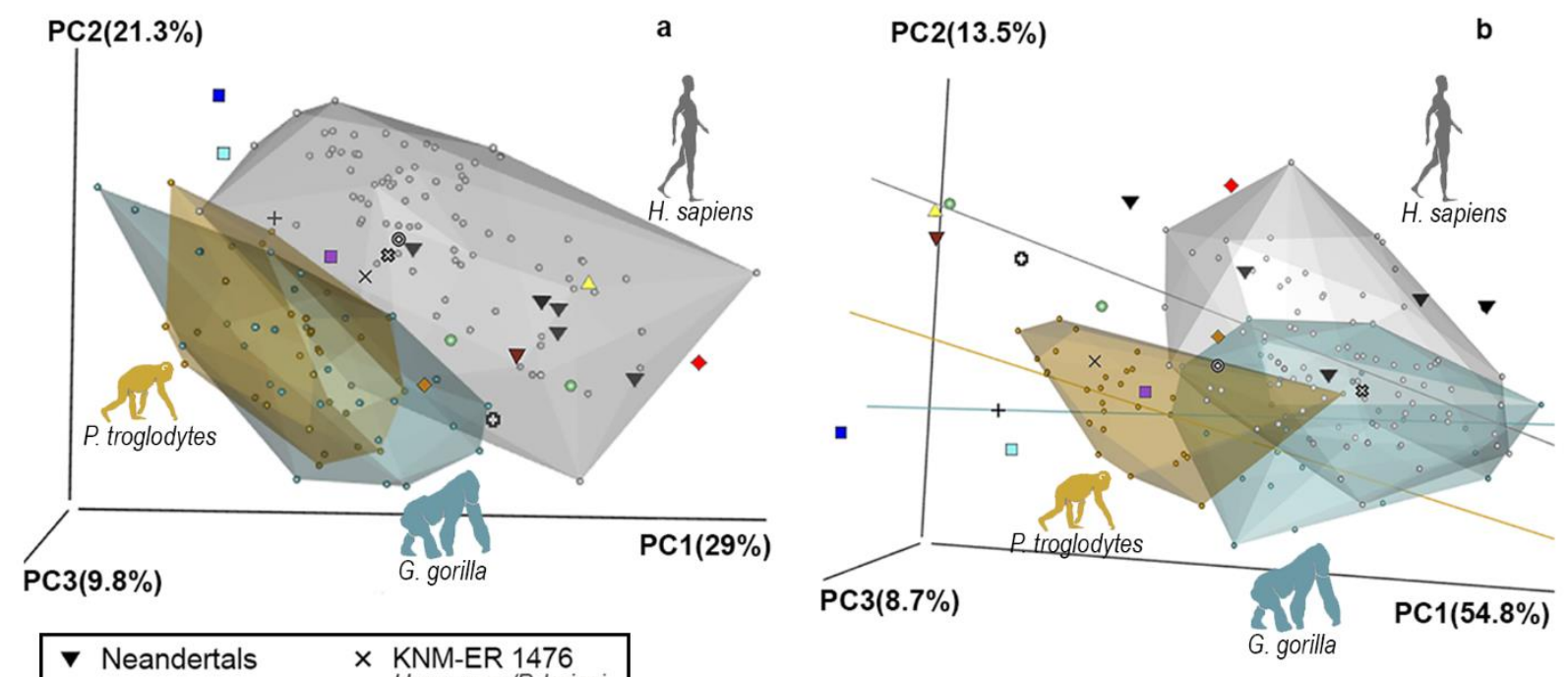

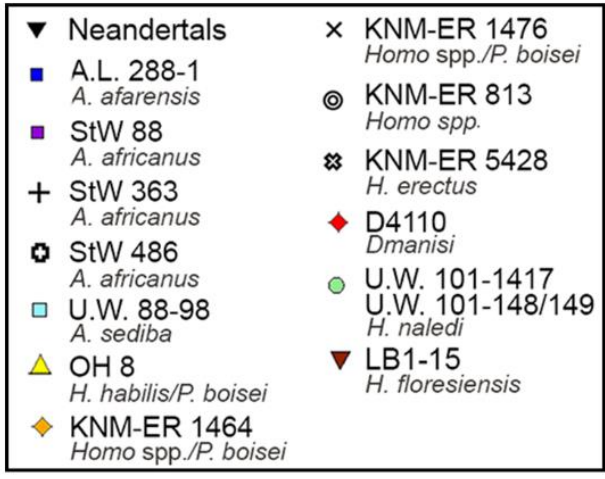
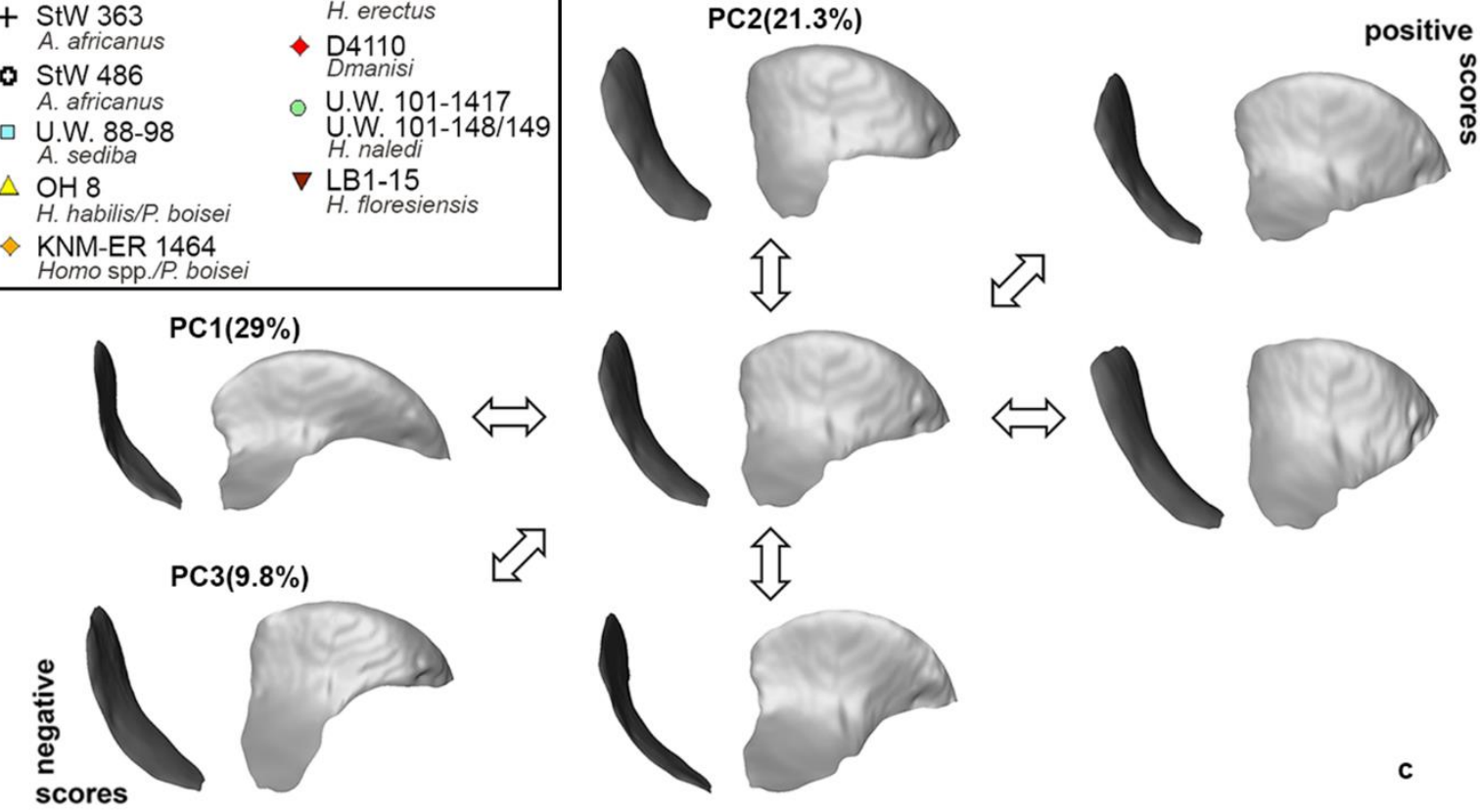

c

Figure 7. Lateral malleolar facet. Shape space 3D PCA plot (a) and form space 3D PCA plot (b).

Shape changes along the first three shape PCs (c) in frontal (left) and lateral (right) views. 


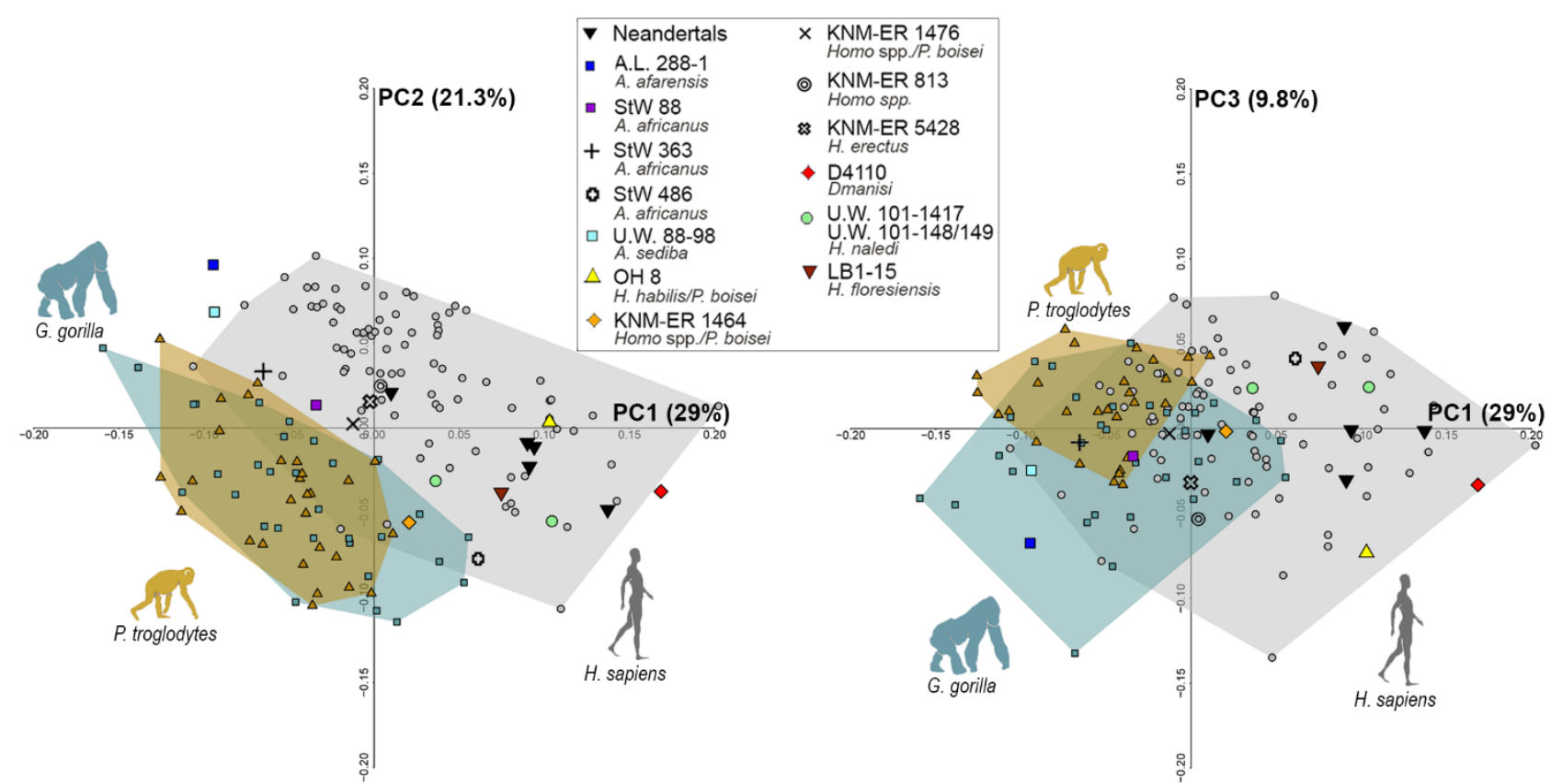

Figure 8. PCA of the lateral malleolar facet in shape space depicting PC1 vs. PC2 (left) and PC1 vs. PC3 (right). 

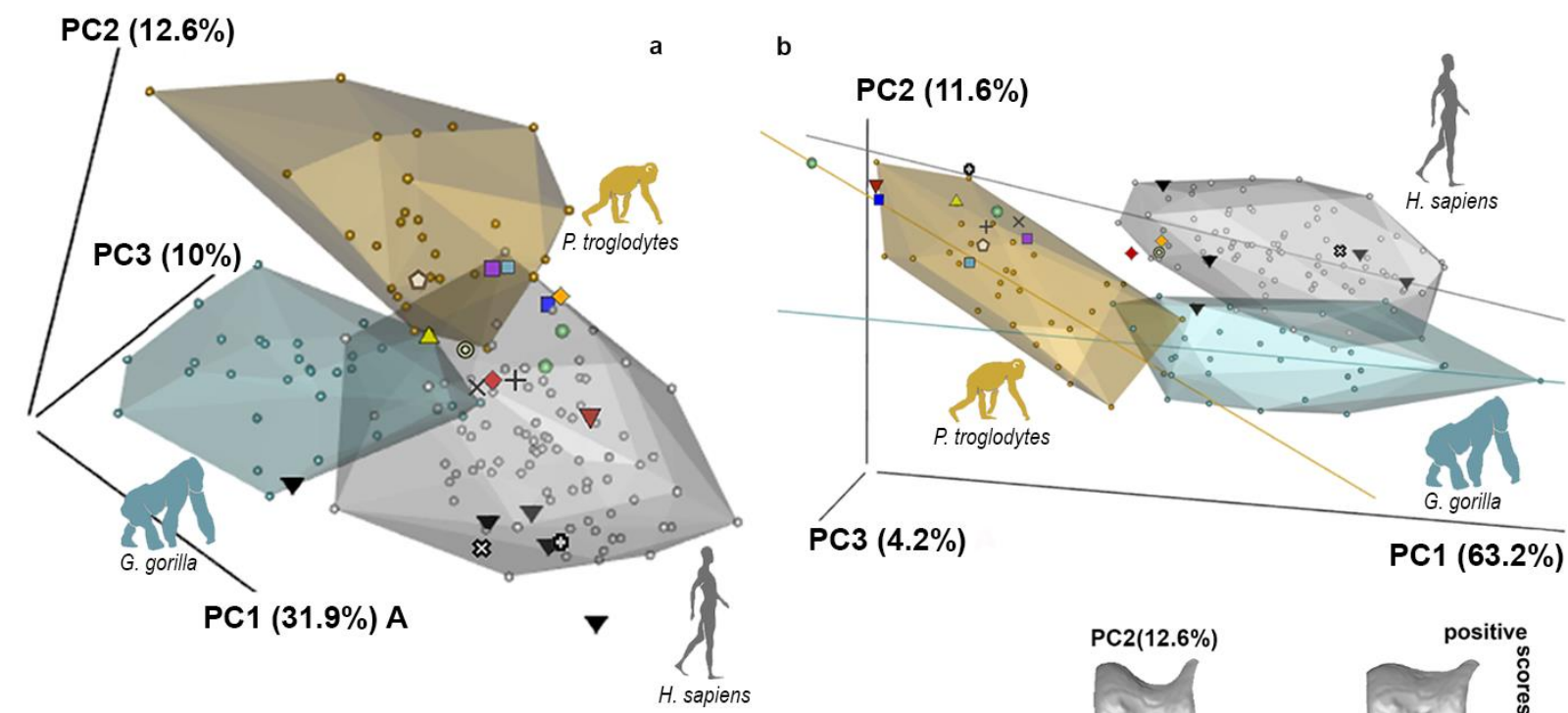

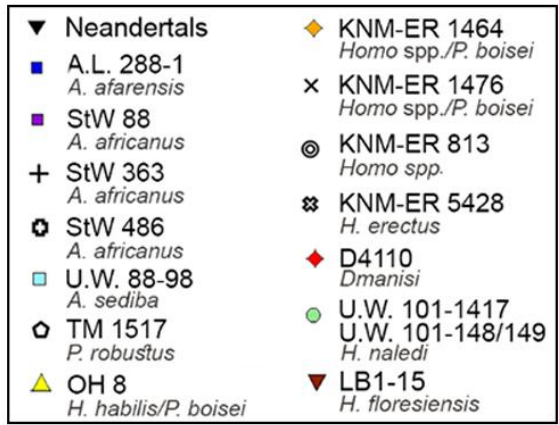
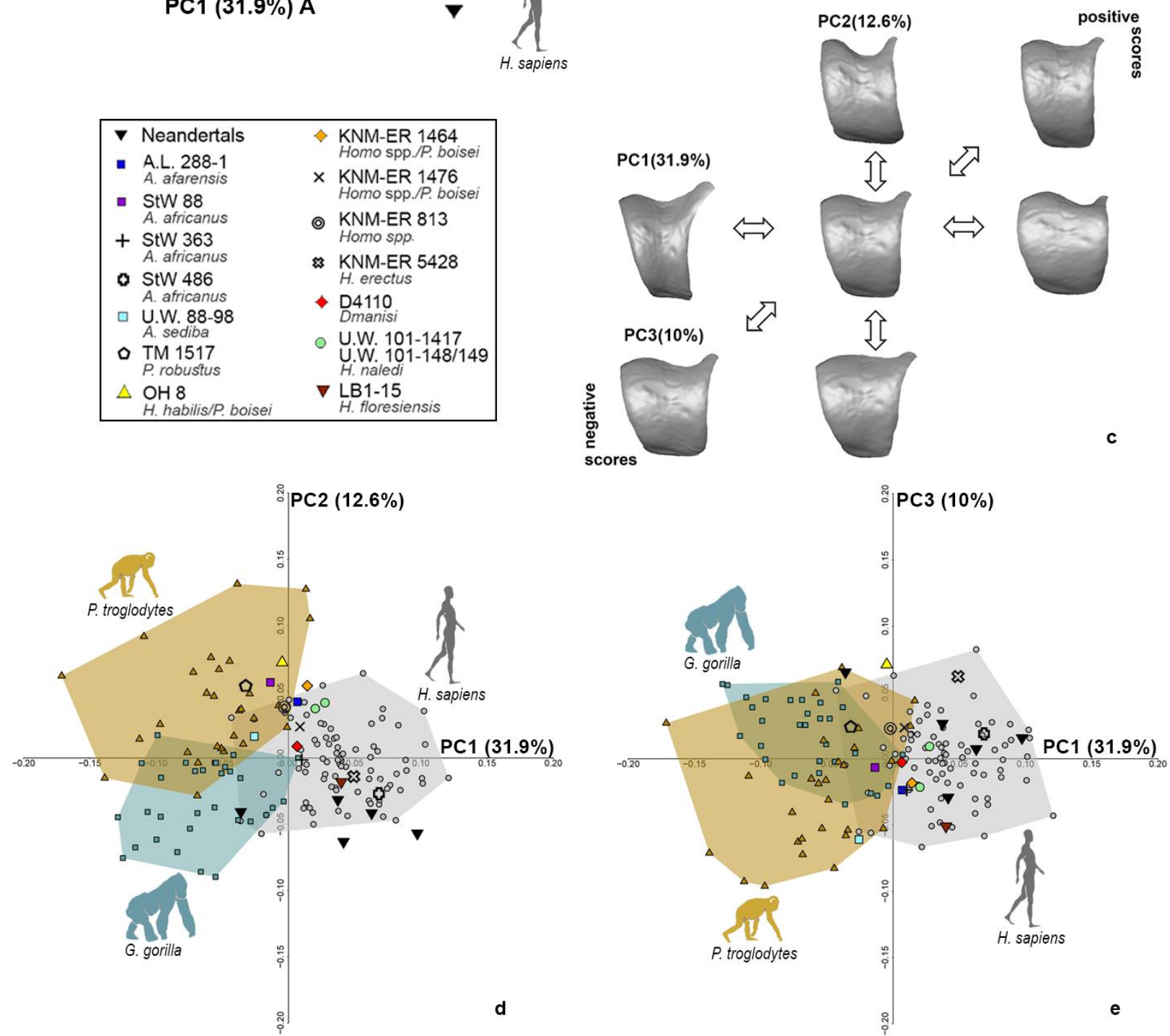

Figure 9. Trochlea. Shape space 3D PCA plot (a) and form space 3D PCA plot (b). Shape changes along the first three shape PCs (c) in dorsal view. PCA of the trochlea in shape space depicting PC1 vs. PC2 (d) and PC1 vs. PC3 (e). 


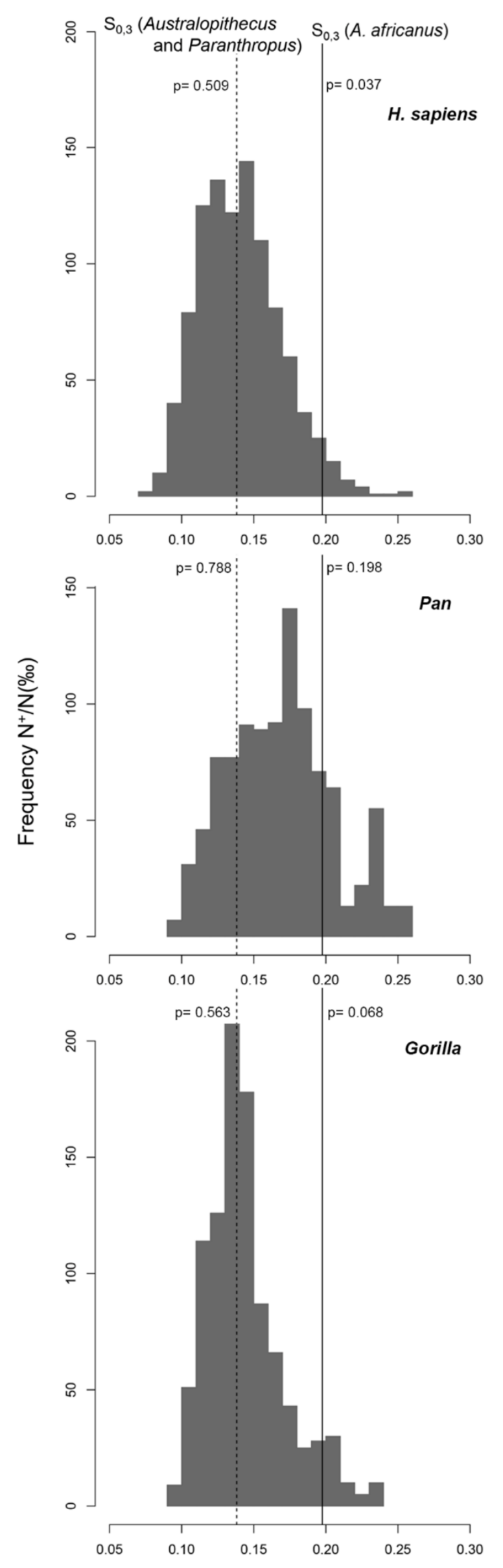

Figure 10. Histograms of phenetic distances of $A$. africanus (black line) and combined A.L. 288-1, U.W. 88-98 and TM1517 (dashed line) with $H$. sapiens, Pan and Gorilla using the Procrustes shape coordinates of the trochlea. 

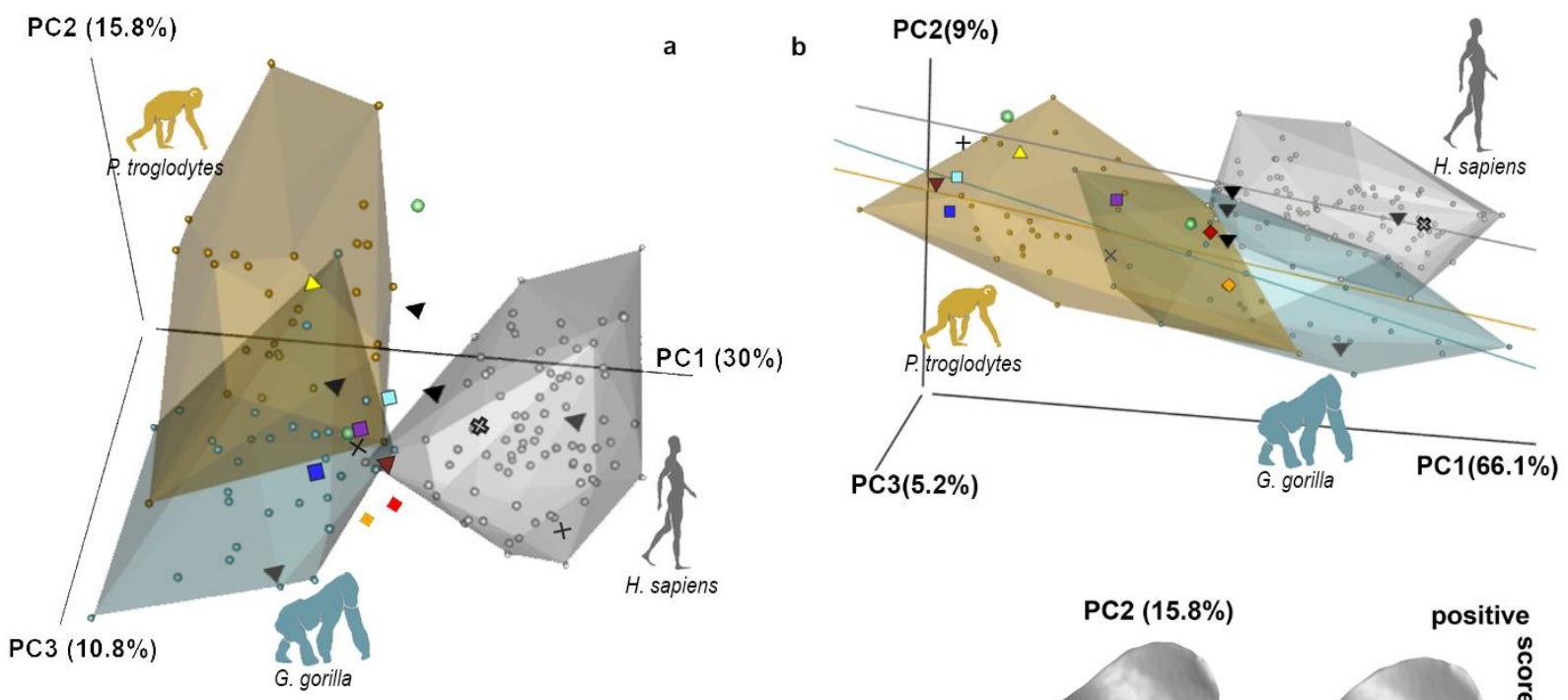

\begin{tabular}{|c|c|c|c|}
\hline & Neandertals & & $\begin{array}{l}\text { KNM-ER } 1464 \\
\text { Homo spp./P. boisei }\end{array}$ \\
\hline & $\begin{array}{l}\text { A.L. 288-1 } \\
\text { A. afarensis }\end{array}$ & $x$ & $\begin{array}{l}\text { KNM-ER } 1476 \\
\text { Homo spp./P. boisei }\end{array}$ \\
\hline & $\begin{array}{l}\text { StW } 88 \\
\text { A. africanus }\end{array}$ & $\approx$ & KNM-ER 5428 \\
\hline & $\begin{array}{l}\text { StW } 363 \\
\text { A. africanus }\end{array}$ & & D4110 \\
\hline & $\begin{array}{l}\text { U.W. 88-98 } \\
\text { A. sediba }\end{array}$ & 0 & U.W. 101-1417 \\
\hline$\triangle$ & $\triangle \mathrm{OH} 8$ & & H. naledi \\
\hline & & & $\begin{array}{l}\text { LB1-15 } \\
\text { H. floresiensis }\end{array}$ \\
\hline
\end{tabular}
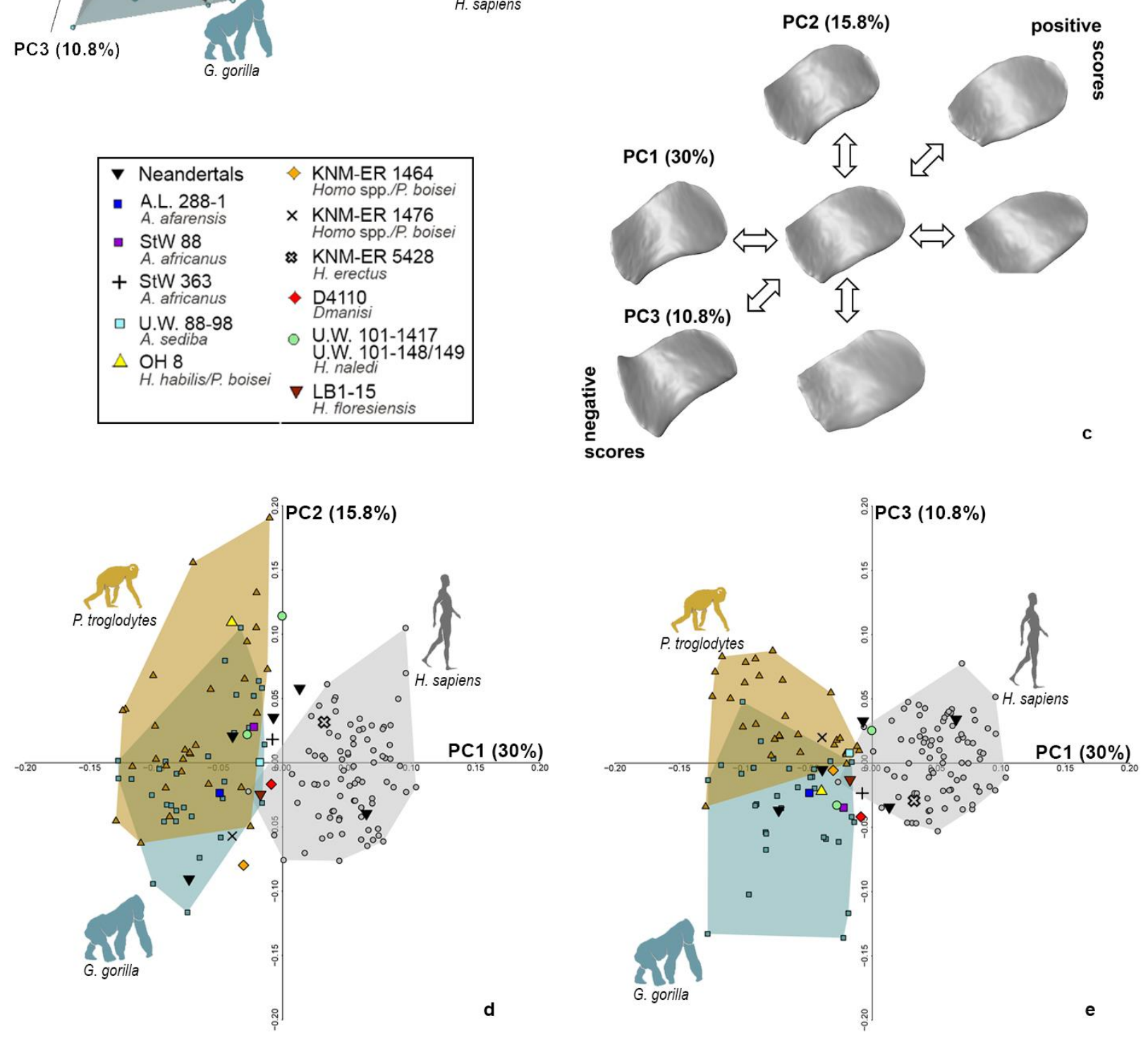

Figure 11. Posterior calcaneal facet. Shape space 3D PCA plot (a) and form space 3D PCA plot (b). Shape changes along the first three shape PCs (c) in plantar view. PCA of the posterior calcaneal facet in shape space depicting PC1 vs. PC2 (d) and PC1 vs. PC3 (e). 

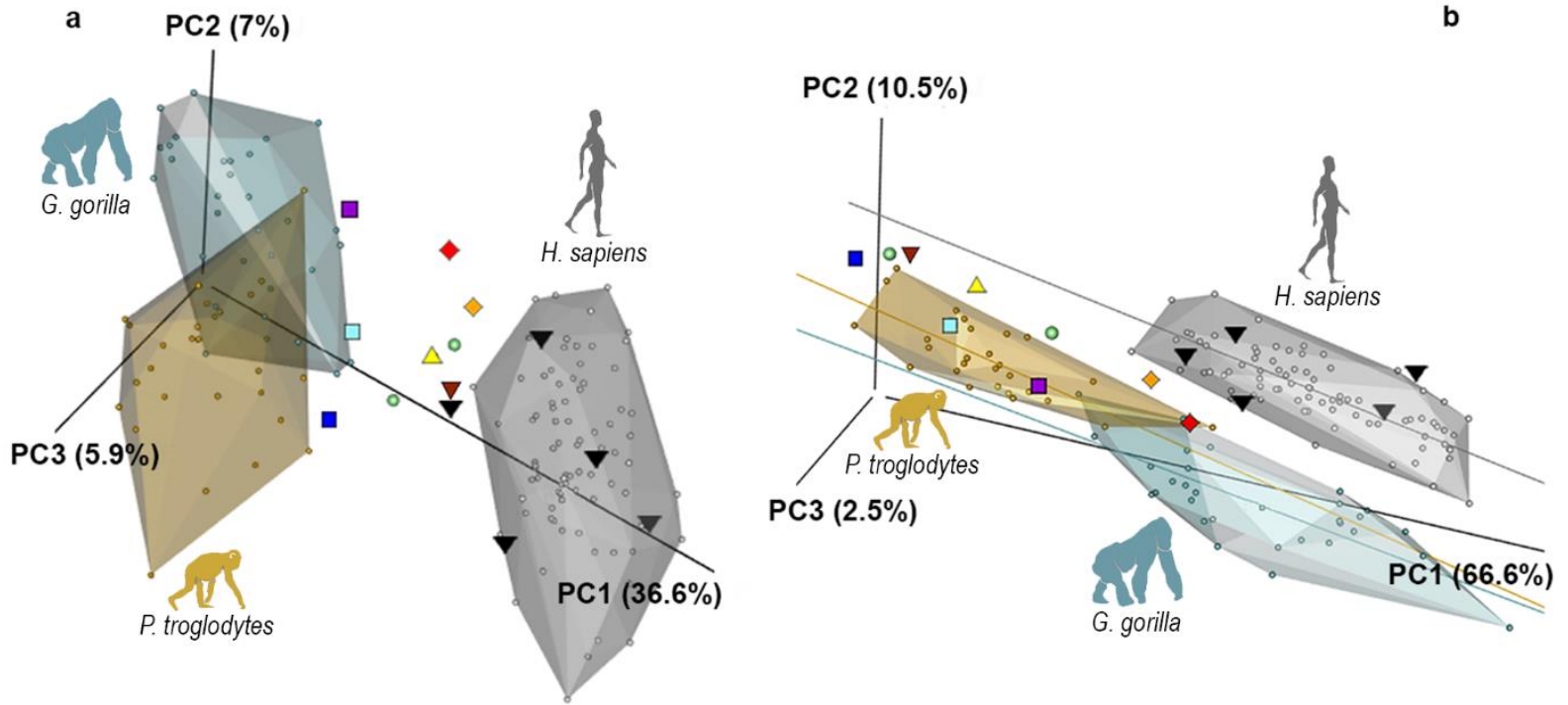

\begin{tabular}{|c|c|c|}
\hline & Neandertals & $\diamond \begin{array}{l}\text { KNM-ER } 1464 \\
\text { Homo spp./P. boisei }\end{array}$ \\
\hline & $\begin{array}{l}\text { A.L. } 288-1 \\
\text { A. afarensis }\end{array}$ & $\begin{array}{l}\text { Homo spp./P. Dolsel } \\
\text { D4110. }\end{array}$ \\
\hline 口 & $\begin{array}{l}\text { StW } 88 \\
\text { A. africanus }\end{array}$ & $\begin{array}{l}\text { Dmanisi } \\
\text { U.W. 101-1417 }\end{array}$ \\
\hline & $\begin{array}{l}\text { U.W. } 88-98 \\
\text { A. sediba }\end{array}$ & $\begin{array}{l}\text { U.W. 101-148/149 } \\
\text { H. naledi }\end{array}$ \\
\hline & $\begin{array}{l}\mathrm{OH} 8 \\
\text { H. habilis/P. boisei }\end{array}$ & $\begin{array}{l}\boldsymbol{\nabla} \text { LB1-15 } \\
\text { H. floresiensis }\end{array}$ \\
\hline
\end{tabular}
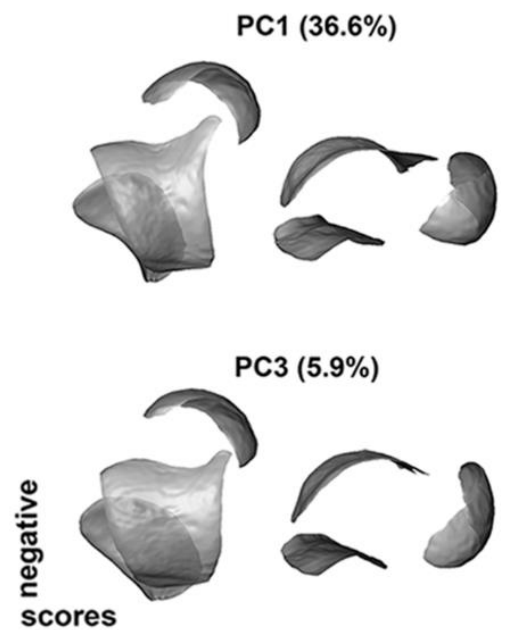

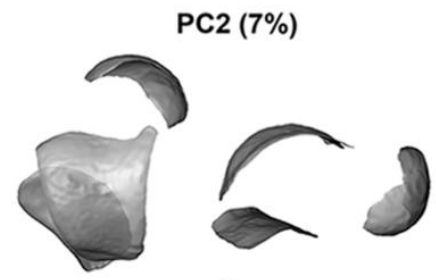

ઈ
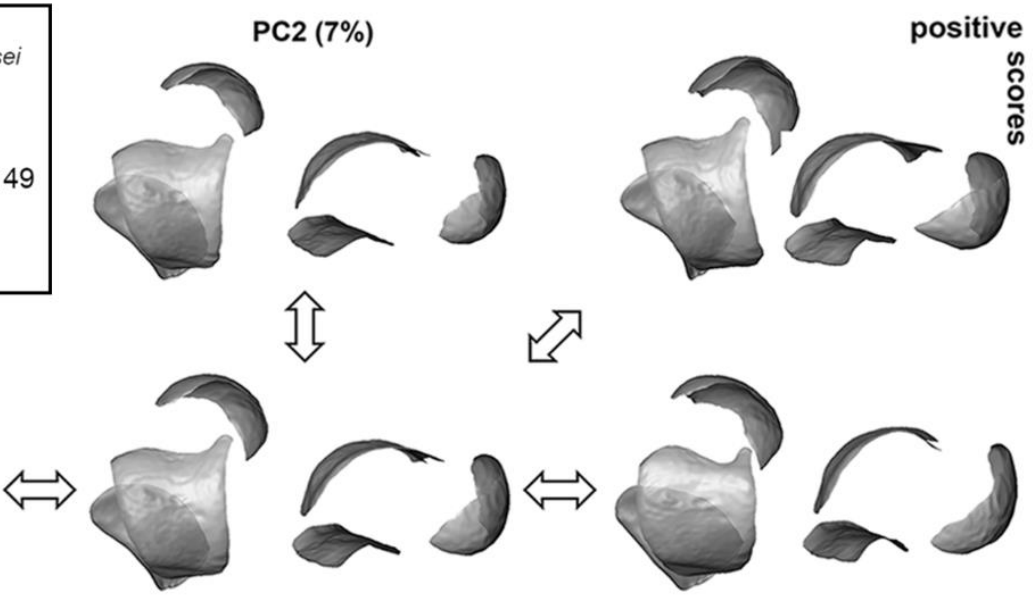

$\hat{5}$
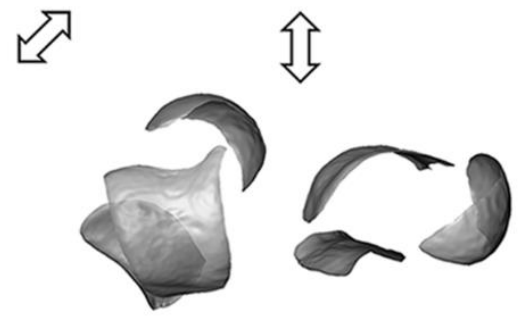

Figure 12. Combined trochlea, and navicular and posterior calcaneal facets. Shape space 3D PCA plot (a) and form space 3D PCA plot (b). Shape changes along the first three shape PCs (c) in dorsal (left) and medial (right) views. 


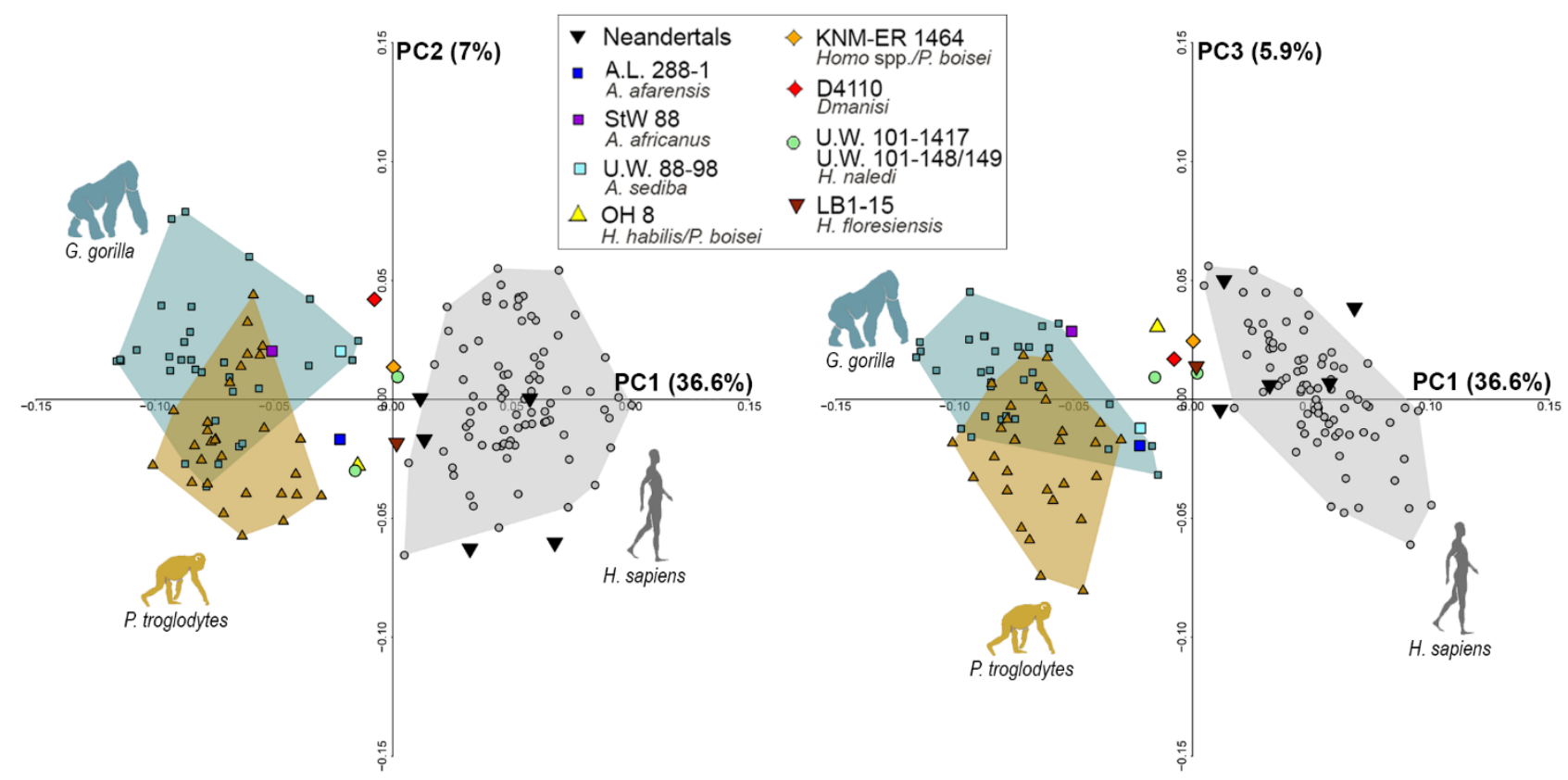

Figure 13. PCA of the combined trochlea, and navicular and posterior calcaneal facets in shape space depicting PC1 vs. PC2 (left) and PC1 vs. PC3 (right). 